\title{
The Complexity Analysis for Price Game Model of Risk-Averse Supply Chain Considering Fairness Concern
}

\author{
Huang Yi-min $\mathbb{D},{ }^{1}$ Li Qiu-xiang $\mathbb{D},^{2}$ and Zhang Yu-hao $\mathbb{D}^{3}$ \\ ${ }^{1}$ School of Management \& Economics, North China University of Water Resources and Electric Power, Zhengzhou 450046, China \\ ${ }^{2}$ Institute of Management Science and Engineering, Henan University, Kaifeng 475004, China \\ ${ }^{3}$ School of Business, Henan University, Kaifeng 475004, China
}

Correspondence should be addressed to Li Qiu-xiang; lqxkycg@163.com and Zhang Yu-hao; zyhydcg@163.com

Received 6 April 2018; Revised 2 September 2018; Accepted 5 September 2018; Published 2 December 2018

Academic Editor: Sergio Gómez

Copyright (C) 2018 Huang Yi-min et al. This is an open access article distributed under the Creative Commons Attribution License, which permits unrestricted use, distribution, and reproduction in any medium, provided the original work is properly cited.

This paper, considering risk aversion and fair concern, establishes a dynamic price game model of a dual-channel supply chain in which dual-channel retailer sells products through traditional channel and online channel and the online retailer only sells products through online channel. The stability of the system and the influences of different parameter values on utilities are analyzed emphatically using game theory and nonlinear dynamic theory, such as $2 \mathrm{D}$ and $3 \mathrm{D}$ bifurcation diagram, parameter plot basin, chaos attractor, and sensitivity to initial value. The results find that the system is more likely to lose stability and fall into chaos with the customer demand fluctuating greatly. The system enters into chaos through flip bifurcation with the increase of the price adjustment speed; adjusting the risk-aversion levels or the fairness concern levels of the two retailers can make the system be in a stable state or delay the occurrence of system instability. When the system is in chaos, the average utility of the online retailer will decrease and one of the dual-channel retailers will increase. Using the state feedback control method, the system can return to a stable state from chaos by selecting appropriate control parameters. The research of this paper is of great significance to the decision-makers' price decision and supply chain operation management.

\section{Introduction}

The rapid development of information technology and the Internet has provided good conditions and development space for the establishment of online channel. The dual-channel sales model is conducive to expanding market share and increasing profits, as well as exacerbating channel competition [1]. Scholars have extensively studied the contract and coordination of dual-channel supply chain based on behavioral factors.

Behavioral factors have great influence on the operation decisions of the supply chain. Related literatures have studied the optimal decision-making, contract coordination, and profit distribution of the risk-aversion supply chain. When decision-makers have risk-aversion behavior, standard repurchase contracts or profit distribution contracts cannot coordinate the supply chain [2]. Yu et al. [3] constructed a $\mathrm{CVaR}$ model of risk-averse supply chain and revealed the influences of the risk-aversion behavior of participants on the optimal order quantity, wholesale price, and supply chain coordination. Qinghua [4] analyzed the coordination problem of the two-level risk-aversion supply chain under the income-sharing contract. $\mathrm{Wu}$ et al. [5] discussed the manufacturer's optimal decision and used simulation experiments to explain how the risk-aversion behavior affects the manufacturer's decision-making. Li and Zhang [6] studied the optimal price strategies for risk-aversion dual-channel supply chains under centralized and decentralized decisionmaking. Li et al. [7] and Golpîra [8] used the CVaR model to measure retailers' risk-aversion levels; the former studied the perishable product dual-channel supply chain with external demand depending on price, and the latter proposed a supply chain network design model for risk-aversion retailer. Amin-Naseri and Khojasteh [9] and Du et al. [10] studied the Stackelberg model of a two-stage supply chain with retailer' risk-aversion behavior and found that the retailer's risk-aversion level is in the same direction with the manufacturer's wholesale price and the entire supply 
chain performance. The above literatures mainly analyze the effects of decision-makers' risk-aversion behaviors on the optimal decision-making and coordination of supply chains. However, in most cases, the supply chain is in a disequilibrium state; it is very important to study how the risk attitude of the decision-maker affects the dynamic evolution process of the supply chain system.

Behavioral studies have found that people pay great attention to fairness in real life, and many empirical or experimental studies have confirmed the existence of fair concern behavior tendencies. Under the influence of fair concern behavior, when competitors feel unfair, they will take actions to achieve the purpose of punishing the other party at the expense of their own interests [11].

The interest distribution between suppliers and retailers will trigger the occurrence of fair concern behavior tendency. Cui et al. [12] discussed the impact of fair concerns on the coordination of the second-order supply chain and found that manufacturers can achieve the coordination of maximum profit and maximum utility of the supply chain with a simple wholesale price when supply chain members considered fair concerns. Du et al. [13] studied the influence of fair concern behavior on supply chain contract coordination and verified that the retailer's fair concern behavior will not change the coordination status of the supply chain. Zhang et al. [14] introduced the retailer's fair concern behavior into the differential pricing strategy of the closed-loop supply chain and found that the fair concern behavior is an effective means for the retailer to obtain the profit distribution. Pavlov and Katok [15] treated fair concern behavior as private information of competitors and used experiments to demonstrate the impact of fair concern on supply chain coordination. Considering retailers' service investment, Q. $\mathrm{H}$. $\mathrm{Li}$ and $\mathrm{B}$. $\mathrm{Li}$ [16] analyzed the dual-channel Stackelberg model and found that supply chain performance increases with the level of fair concerns of retailers; when retailers consider service and fair concerns at the same time, fixed wholesale prices cannot coordinate the entire supply chain.

Zhang and Ma [17] established a dynamic vertical Nash equilibrium model and a dynamic Stackelberg model, respectively, and found that too much concern for fairness is not always good for retailers to get profits, but the paper does not consider risk-aversion behaviors. Yang and Sun [18] considered two scenarios: only the manufacturer has fair concern behavior and only the retailer has fair concern behavior, and found that manufacturer's fair concern behavior will raise wholesale prices and increase profits, and retailer's fair concern will reduce wholesale prices and get more profits. Niu et al. [19] studied the impact of channel power and fair concern behavior on the decision-making of the dualchannel supply chain system and found that fair concern behavior can effectively reduce the incentive for suppliers to sell in online channel. Li et al. [20] studied a supply chain system consisting of a manufacturer and a traditional retailer and found that it cannot achieve channel coordination no matter whether the manufacturer has fair concern behavior or not. Li et al. [21] studied a cooperative advertising strategy considering fairness concern behavior where the retailer is the leader of the market competition and the manufacturer is the follower and found that if only the manufacturer has fair concern behavior, the profits of the manufacturer and the entire system will increase, but the retailer's profit will reduce. Chen et al. [22] studied the influence of retailer's fair concern behavior on supply chain operation. Research showed that the optimal pricing increased with the fair concern behavior and the wholesale price. Nie et al. [23] constructed a Stackelberg game model of the supply chain considering fair concern behavior and discussed the decision-making and coordination issues in the wholesale price contract and repurchase contract, respectively. Under the situation of multiperiodic quality penalty, Zhang et al. [24] established quality decision-making models of logistics service supply chain considering fair preference from the horizontal and vertical level. The simulation results showed that fairness preference had a strong influence on the quality decision of the service supply chain. The above literature studied the impact of fairness concern behavior on supply chain price decision and coordination. Different from the above literature, considering the retailer's risk-aversion behavior and the fair concern behavior and taking the dual-channel supply chain as the research object, this paper will study the evolution mechanism of the dynamic price decision model.

The dynamic game model and its evolutionary mechanism have always been a hot issue for scholars. Puu [25] first discovered the existence of singular attractor in the duopoly Cournot model and briefly discussed the competition situation of trio oligopolistic game. Lu [26] studied master-slave Bertrand price game model and extended the model to three-dimensional differential equations and found that when the price adjustment coefficient is large, there occur bifurcation and chaos in the system. Liu et al. [27] established a four-oligopoly dynamic price game model based on the nonlinear demand and the difference of manufacturer's cost and simulated the dynamic evolution process of the system using system dynamics. Si and Ma [28] constructed a triopoly output game model with multiple delays in the competition of green products and found that the system loses stability and increases complexity if delay parameters exceed a certain range. Xie et al. [29] considered a supply chain and focused on the retailer's bundling strategy and investigated the impact of the stochastic demand and manufacturers' decisions on the bundling strategy. Ma and Sun [30] established a four-oligopoly mixed game model of upstream and downstream under the influence of "the Belt and Road Initiative" launched by the Chinese government and examined the complexity of its characteristics. Xiao et al. [31, 32] proposed a security system that applies the indirect reciprocity principle to combat attacks in wireless networks, derive the optimal strategy and the corresponding stationary reputation distribution, and evaluate the stability condition of the optimal strategy. Huang and Li [33] developed a dynamic Stackelberg game model of the supply chain consumers' attitudes to risks for probabilistic products and probabilistic selling and analyzed the influences of decision variables and parameters on the stability and entropy of an asymmetric dual-channel supply chain system. Wu and Ma [34] considered a dynamic epiphytic supply chain game model with two players and 
product horizontal diversification and found the system had two routes to chaos: flip bifurcation and NeimarkSacker bifurcation.

In view of this, based on the dual-channel supply chain environment, considering that the two retailers have risk-aversion and fair concern behaviors, this paper will construct a dynamic price game model of dual-channel supply chain using game theory and nonlinear dynamic theory and focus on the analysis of the stability characteristics of equilibrium point and the effect of parameters on the system stability and profits. On this basis, the state feedback control method is used to control the chaotic behavior of the system. The research in this paper has great guidance significance for decision-maker's price decision and supply chain operation management.

\section{Model Description and Construction}

2.1. Model Description. In this paper, we study a dual-channel supply chain in which the two retailers have risk-aversion behavior and fair concern behavior, the dual-channel retailer sells products through traditional channel and online channel, and the online retailer only sells products through online channel (as shown in Figure 1). The two retailers make the price competition and obtain the maximum profit through the price adjustment and the game.

where $p_{1}$ and $p_{2}$ are the product prices of the dual-channel retailer in traditional channel and online channel and $p_{3}$ is the product price of the online retailer in online channel.

\subsection{Model Hypothesis}

(1) The two retailers have limited rationality, riskaversion behavior, and fair concern behavior

(2) Market demand $a(a>0)$ is uncertain; satisfies $a=\bar{a}+\varepsilon$, where $\bar{a}$ is the basic market demand and $\varepsilon$ is a random part of the market demand; and follows normal distribution $\varepsilon\left(0, \sigma^{2}\right)$

(3) The two retailers have the same product cost (c), and their operating costs are zero

2.3. Model Construction. The demand functions of the two retailers are expressed as follows:

$$
\left\{\begin{array}{l}
D_{1}=\theta a-b p_{1}+k p_{2}+k p_{3}, \\
D_{2}=(1-\theta) a-b p_{2}+k p_{1}+k p_{3} \\
D_{3}=(1-\theta) a-b p_{3}+k p_{1}+k p_{2},
\end{array}\right.
$$

where $D_{1}$ and $D_{2}$ are customer demands of the dualchannel retailer in traditional channel and online channel and $D_{3}$ is customer demand of online retailer in online channel. $\theta \in(0,1)$ expresses the loyalty of consumers to traditional channel, and $\theta a$ is the number of goods that consumers buy from traditional channel; $b$ and $k$ are price elasticity and cross-price elasticity of product demand, respectively, which satisfied $b \geq k>0$.

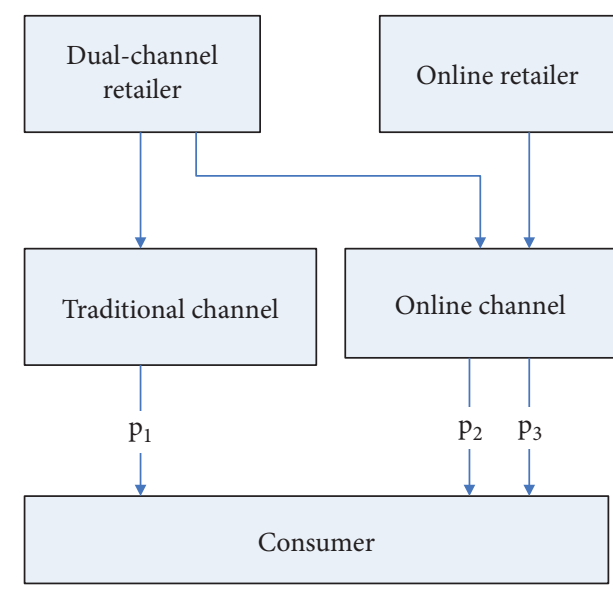

FIGURE 1: Dual-channel supply chain.

Suppose that the price decisions of the two retailers occur within the discrete time period $(t=1,2,3, \ldots)$; the price of each retailer in the $t$ period is $p_{i}(t)$; the profit functions of the two retailers are:

$$
\left\{\begin{array}{l}
\pi_{1}(t)=\left[p_{1}(t)-c\right] D_{1}(t)+\left[p_{2}(t)-c\right] D_{2}(t), \\
\pi_{2}(t)=\left[p_{3}(t)-c\right] D_{3}(t),
\end{array}\right.
$$

where $c$ is the product cost of the two retailers and $\pi_{i}(t)$ $(i=1,2)$ are the total profits of the two retailers in the dual-channel supply chain, letting $\pi_{d}=\left[p_{2}(t)-c\right] D_{2}(t)$ which expresses the profit of dual-channel retailer obtained from the online channel.

Because of the uncertainty of customer's demand, the two retailers have financial risks and should consider the influence of the risk attitude on price decision. The exponential utility equation, which has important application in financial risk assessment and decision-making theory, is used to measure the impact of risk-aversion behavior on retailers' utility acquisition. The exponential utility equation is expressed as follows: $E(\pi)=-e^{-\pi / R}$, where $R$ indicates the risk tolerance level of the decision-maker. $R<\infty$ expresses that the decision-maker has the risk-aversion behavior, and $R=\infty$ means that the decision-maker is risk neutral. Assume that the profits of risk-averse decision-makers obey the normal distribution; the expected utility function of the decisionmaker can be expressed as follows:

$$
E(U)=E(\pi)-\left[\frac{\operatorname{var}(\pi)}{2 R}\right],
$$

where $E(\pi)$ is the expected profit of the decision-maker and $\operatorname{var}(\pi)$ is the profit's variance. The utility function equations of the two risk-aversion retailers are as follows:

$$
\left\{\begin{array}{l}
E\left(U_{1}\right)=E\left(\pi_{1}\right)-\frac{\left[\operatorname{var}\left(\pi_{1}\right)\right]}{2 R_{1}}, \\
E\left(U_{2}\right)=E\left(\pi_{2}\right)-\frac{\left[\operatorname{var}\left(\pi_{2}\right)\right]}{2 R_{2}} .
\end{array}\right.
$$


Du et al. [13] gave the retailer's utility function as follows:

$$
U_{r}=\pi_{r}-\beta\left(\pi_{m}-\pi_{r}\right),
$$

where $\pi_{m}$ and $\pi_{r}$ represent the profits of the manufacturer and retailer, respectively, and $\beta$ denotes fairness concern coefficient; the fairness feeling of the retailer depends on the comparison of the absolute profit of the manufacturer and retailer.

Cui et al. [12] thought the retailer's fairness feeling depended on the comparison of relative profit of the manufacturer and the retailer and gave the retailer's fairness utility function as follows:

$$
u_{r}(w, p)=\pi_{r}(w, p)+f_{r}(w, p)
$$

where

$$
\begin{aligned}
f_{r}(w, p)= & -\alpha \max \left[\gamma \Pi(w, p)-\pi_{r}(w, p), 0\right] \\
& -\beta \max \left[\pi_{r}(w, p)-\gamma \Pi(w, p), 0\right] .
\end{aligned}
$$

$\Pi(w, p)$ and $\pi(w, p)$ denote the monetary reward of the manufacturer and retailer, respectively; $\alpha$ and $\beta$ are the sensitive coefficients of utility loss and utility increase, respectively; and $\gamma$ is a fair perception of relative profit coefficient, which depends on the comparison of the relative profit between the retailer and the manufacturer and expresses that the retailer chooses the partial profit of the manufacturer $\gamma \Pi(w, p)$ as the reference index. If $\gamma \Pi(w, p)-\pi_{r}(w, p)>0$, the utility of the retailer will be reduced; on the other hand, the utility of the retailer will increase.

According to the actual market situation, the fair feeling of the dual-channel retailer is related to the comparison of the absolute profits of the two retailers on the online channel; the fair feeling of the online retailer depends on the comparison with the relative profit and the absolute profit of the dual-channel retailer. Thus, the utility function equations of the two risk-averse retailers can be obtained in a discrete time period $(t=$ $1,2,3, \ldots)$ :

$$
\left\{\begin{array}{l}
E\left[U_{1}(t)\right]=E\left[\pi_{1}(t)\right]-\frac{\sigma^{2}\left\{\theta\left[p_{1}(t)-c\right]+(1-\theta)\left[p_{2}(t)-c\right]\right\}^{2}}{2 R_{1}}-\lambda_{1}\left\{E\left[\pi_{2}(t)\right]-E\left[\pi_{d}(t)\right]\right\}, \\
E\left[U_{2}(t)\right]=E\left[\pi_{2}(t)\right]-\frac{\sigma^{2}(1-\theta)^{2}\left[p_{3}(t)-c\right]^{2}}{2 R_{2}}-\lambda_{2}\left\{\gamma E\left[\pi_{1}(t)\right]-E\left[\pi_{2}(t)\right]\right\},
\end{array}\right.
$$

where $\lambda_{1}$ and $\lambda_{2} \in(0,1)$ represent the fairness concern coefficients of the two retailers.

The marginal utilities of the two retailers can be obtained by taking the first-order partial derivatives of utility functions for $p_{1}, p_{2}$, and $p_{3}$ :

$$
\left\{\begin{array}{l}
\frac{\partial E\left[U_{1}(t)\right]}{\partial p_{1}(t)}=\frac{\theta \sigma^{2}\left[\theta\left(c-p_{1}(t)\right)+(1-\theta)\left(c-p_{2}(t)\right)\right]}{R_{1}}+A \\
\frac{\partial E\left[U_{1}(t)\right]}{\partial p_{2}(t)}=\frac{\sigma^{2}(\theta-1)\left[(1-\theta)\left(c-p_{2}(t)\right)+\theta\left(c-p_{1}(t)\right)\right]}{R_{1}}+B \\
\frac{\partial E\left[U_{2}(t)\right]}{\partial p_{3}(t)}=\frac{\sigma^{2}(-1+\theta)^{2}\left[c-p_{3}(t)\right]}{R_{2}}+C
\end{array}\right.
$$

where

$$
\begin{aligned}
A= & -c k+a \theta+b\left[c-2 p_{1}(t)\right]+2 k\left(2+\lambda_{1}\right) p_{2}+k\left(1-\lambda_{1}\right) p_{3}(t), \\
B= & c k\left(-1+\lambda_{1}\right)-a(-1+\theta)\left(1+\lambda_{1}\right)+k\left(2+\lambda_{1}\right) p_{1}(t)+k p_{3}(t) \\
& +b\left(1+\lambda_{1}\right)\left[c-2 p_{2}(t)\right], \\
C= & 2 c \gamma k \lambda_{2} b\left(1+\lambda_{2}\right)\left[c-2 p_{3}(t)\right]-a(-1+\theta)\left(1+\lambda_{2}\right) \\
& +k\left(1+\lambda_{2}-\gamma \lambda_{2}\right) p_{1}(t)+k\left(1+\lambda_{2}-\gamma \lambda_{2}\right) p_{2}(t) .
\end{aligned}
$$

The two retailers can only get part of the market information when they make decisions. Therefore, the two retailers will adjust the price decisions of the next period according to the marginal utility of this period. When the marginal utility of this period is greater than zero, the retailer will increase the price adjustment speed in the next period; in contrast, when the marginal utility of this period is less than zero, the retailer will reduce the price adjustment speed in the next stage. The price adjustment mechanism is as follows:

$$
p_{i}(t+1)=p_{i}(t)+\alpha_{i} p_{i}(t) \frac{\partial E\left[U_{i}(t)\right]}{\partial p_{i}(t)}
$$

where $\alpha_{i}>0(i=1,2,3)$ express the price adjustment speed of the two retailers in traditional channel and online channel.

A three-dimensional discrete dynamic price game model of the dual-channel supply chain is set up as follows:

$$
\left\{\begin{array}{l}
p_{1}(t+1)=p_{1}(t)+\alpha_{1} p_{1}(t) \frac{\partial E\left[U_{1}(t)\right]}{\partial p_{1}(t)} \\
p_{2}(t+1)=p_{2}(t)+\alpha_{2} p_{2}(t) \frac{\partial E\left[U_{1}(t)\right]}{\partial p_{2}(t)} \\
p_{3}(t+1)=p_{3}(t)+\alpha_{3} p_{3}(t) \frac{\partial E\left[U_{2}(t)\right]}{\partial p_{2}(t)}
\end{array} .\right.
$$




\section{The Stability of the System (12)}

By making $p_{i}(t+1)=p_{i}(t) \quad(i=1,2,3)$, eight equilibrium solutions can be obtained and expressed as follows:
$E_{1}=(0,0,0)$ and $E_{8}=\left(p_{1}^{*}, p_{2}^{*}, p_{3}^{*}\right)$; the expressions of $E_{2}$, $\ldots, E_{7}$ are shown in the appendix.

The following analyzes the stability of each equilibrium point; the Jacobi matrix of system (12) is as follows:

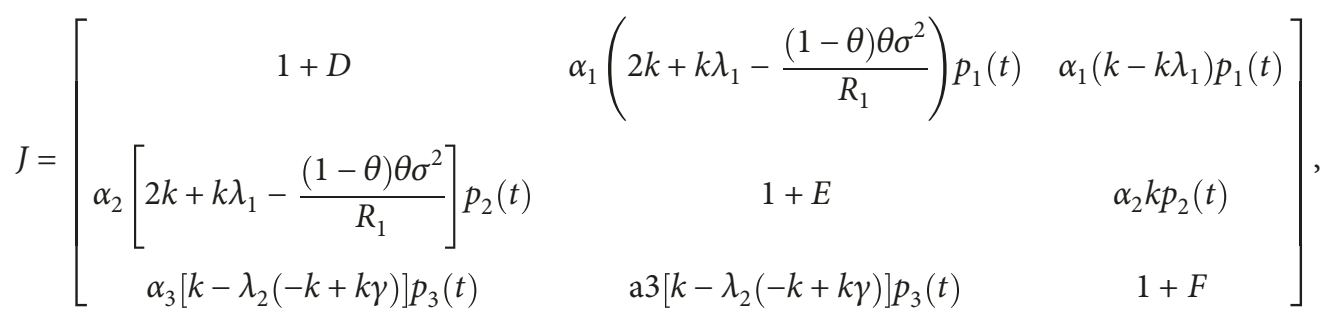

where

$$
\begin{aligned}
D= & \alpha_{1}\left[b c-k c+a \theta-2 b p_{1}(t)+3 k p_{2}(t)\right]+\alpha_{1}\left(-2 b-\frac{\theta^{2} \sigma^{2}}{R_{1}}\right) p_{1}(t) \\
& -\frac{\alpha_{1} \theta \sigma^{2}\left[-c+p_{2}(t)\right](1-\theta)+\alpha_{1} \theta^{2} \sigma^{2}\left[-c+p_{1}(t)\right]}{R_{1}}, \\
E= & \alpha_{2} b\left(1+\lambda_{1}\right)\left[c-2 p_{2}(t)\right]+\alpha_{2} a(1-\theta)\left(1+\lambda_{1}\right) \\
& +k \alpha_{2}\left[p_{3}(t)+c\left(-1+\lambda_{1}\right)+\left(2+\lambda_{1}\right) p_{1}(t)\right] \\
& +\alpha_{2}\left[-2 b\left(1+\lambda_{1}\right)-\frac{(1-\theta)^{2} \sigma^{2}}{R_{1}}\right] p_{2}(t) \\
& -\alpha_{2}\left\{\frac{\sigma^{2}(1-\theta)^{2}\left[-c+p_{2}(t)\right]+\sigma^{2} \theta(1-\theta)\left[-c+p_{1}(t)\right]}{R_{1}}\right\} \\
F= & \alpha_{3}\left\{b\left(1+\lambda_{2}\right)\left[c-4 p_{3}(t)\right]+a(1-\theta)\left(1+\lambda_{2}\right)\right. \\
& \left.+k\left[\left(1+\lambda 2-\gamma \lambda_{2}\right) p_{1}(t)+\left(1+\lambda_{2}-\gamma \lambda_{2}\right) p_{2}(t)+2 c \gamma \lambda_{2}\right]\right\} \\
& +\frac{\sigma^{2}(-1+\theta)^{2} \alpha_{3}}{R_{2}}\left[c-2 p_{3}(t)\right] .
\end{aligned}
$$

The necessary and sufficient conditions for the stability of the equilibrium point of the system are that all the corresponding eigenvalues are less than one. The equilibrium point is unstable if the nonzero eigenvalue is greater than one.

Take $E_{1}$ as an example; the corresponding Jacobi matrix of $E_{1}$ is

$$
J\left(E_{1}\right)=\left[\begin{array}{ccc}
M & 0 & 0 \\
0 & N & 0 \\
0 & 0 & Q
\end{array}\right],
$$

where

$$
\begin{aligned}
& M=1+\alpha_{1}\left\{c(b-k)+a \theta+\frac{\theta \sigma^{2}[c(1-\theta)+c \theta]}{R_{1}}\right\}, \\
& N=1+\alpha_{2}\left\{c(b-k)+a(1-\theta)+\lambda_{1}[b c+c k+a(1-\theta)]+\frac{c(1-\theta) \sigma^{2}}{R_{1}}\right\}, \\
& Q=1+\alpha_{3}\left\{b c+a(1-\theta)+[b c+2 c k \gamma+a(1-\theta)]+\frac{c(1-\theta)^{2} \sigma^{2}}{R_{2}}\right\} .
\end{aligned}
$$

It is known from the parameter values that $M, N$, and $Q$ are more than 0 and the eigenvalues of $J\left(E_{1}\right)$ are all greater than 1. So $E_{1}$ is an unstable equilibrium point. We can prove that $E_{2}, E_{3}, E_{4}, E_{5}, E_{6}$, and $E_{7}$ are all unstable point in the same way, so $E_{8}$ is the only Nash equilibrium point.

The following analyzes the stability of the Nash equilibrium point $\left(E_{8}\right)$; the expression of the characteristic polynomial of the Jacobi matrix in the Nash equilibrium point can be expressed as follows:

$$
F(\lambda)=A_{0}+A_{1} \lambda+A_{2} \lambda^{2}+\lambda^{3},
$$

where

$$
\begin{aligned}
A_{0}= & -(1+D)(1+E)(1+F)+k \alpha_{2} \alpha_{3}(1+D) \\
& \cdot\left[k-\lambda_{2}(-k+k \gamma)\right] p_{2}(t) p_{3}(t)+\alpha_{1} \alpha_{3}(1+\mathrm{e})\left(k-k \lambda_{1}\right) \\
& \cdot\left[k-\lambda_{2}(-k+k \gamma)\right] p_{1}(t) p_{3}(t)-k \alpha_{1} \alpha_{2} \alpha_{3}\left[k-\lambda_{2}(-k+k \gamma)\right] \\
& \cdot\left(2 k+k \lambda_{1}-\frac{(1-\theta) \theta \sigma^{2}}{R_{1}}\right) p_{1}(t) p_{2}(t) p_{3}(t)-\alpha_{1} \alpha_{2} \alpha_{3}\left(k-k \lambda_{1}\right) \\
& \cdot\left[k-\lambda_{2}(-k+k \gamma)\right]\left(2 k+k \lambda_{1}-\frac{(1-\theta) \theta \sigma^{2}}{R_{1}}\right) p_{1}(t) p_{2}(t) p_{3}(t) \\
& +\alpha_{1} \alpha_{2}(1+F)\left[2 k+k \lambda_{1}-\frac{(1-\theta) \theta \sigma^{2}}{R_{1}}\right]^{2} p_{1}(t) p_{2}(t),
\end{aligned}
$$




$$
\begin{aligned}
A_{1}= & (1+D)(1+E)+(1+D)(1+F)+(1+\mathrm{e})(1+F) \\
& -k \alpha_{2} \alpha_{3}\left[k-\lambda_{2}(-k+k \gamma)\right] p_{2}(t) p_{3}(t)-\alpha_{1} \alpha_{3}\left(k-k \lambda_{1}\right) \\
& \cdot\left[k-\lambda_{2}(-k+k \gamma)\right] p_{1}(t) p_{3}(t)-\alpha_{1} \alpha_{2} \\
& \cdot\left[2 k+k \lambda_{1}-\frac{(1-\theta) \theta \sigma^{2}}{R_{1}}\right]^{2} p_{1}(t) p_{2}(t), \\
A_{2}= & -3-D-E-F .
\end{aligned}
$$

According to the Jury conditions, the sufficient and necessary conditions for the stability of the Nash equilibrium point of the system (12) are as follows:

$$
\left\{\begin{array}{l}
A_{0}+A_{1}+A_{2}+1>0, \\
A_{0}-A_{1}+A_{2}-1<0, \\
A_{0}^{2}-1<0 \\
\left(1-A_{0}^{2}\right)^{2}-\left(A_{1}-A_{0} A_{2}\right)^{2}>0 .
\end{array}\right.
$$

By solving condition (20), the stability domain of system (12) can be obtained. Due to these limitations being so complex, solving the inequality equation (20) is very complicated. If the Nash equilibrium point satisfies the inequality equation (20), we may ensure that system (12) is locally stable. Next, we give the stable region of system (12) through numerical simulation.

According to the current situation and characteristics of the dual-channel supply chain enterprises, the parameter values are as follows: $a=100, b=1, \theta=0.6, k=0.5$, $\lambda_{1}=0.5, \lambda_{1}=0.5, \sigma=20, R_{1}=20, R_{2}=20, c=10$, and $\gamma=$ 0.5 . Based on the stability conditions of the system (12), the three-dimensional stability domains of the system (12) are simulated when $\sigma, R_{1}$, and $R_{2}$ take different values (as shown in Figure 2).

Figure 2 shows the three-dimensional stability regions of system (12) under different parameter values. From Figures 2(a) and 2(b), we can see that the stability region of system (12) decreases with the increase of $\sigma$, which indicates that the greater the demand fluctuation is, the more unstable the system (12) is. From Figures 2(c) and 2(d), when $R_{1}$ or $R_{2}$ increases, the stability range of the price adjustment speed of the corresponding retailer will increase. If the price adjustment speeds of the two retailers are in the stable area, system (12) will achieve a stable state at the Nash equilibrium point after a finite game.

\section{The Numerical Simulation of System (12)}

4.1. The Influence of Price Adjustment Speed on the Stability of the System (12). Through the analysis of the stability region of the system (12), we can see that the price adjustment speed has an important influence on the stability of the system (12). Next, take $\alpha_{3}$ as an example; the influences of $\alpha_{3}$ changing on the stability of the system (12) will be analyzed with different parameter values.
Figure 3 shows the bifurcation diagrams and largest Lyapunov exponents (LLE) with the change of $\alpha_{3}$ when $\alpha_{1}=\alpha_{2}=0.005$. We can see that system (12) is stable when $\alpha_{3}<0.0156$ and enters chaos through period-doubling bifurcation when $\alpha_{3}$ increases. LLE reflect the state of the system (12); when the LLE are negative, the dynamic system (12) remains stable; when the majority of the LLE are positive, the dynamic system (12) falls into chaos. In other words, the larger the positive LLE are, the more chaotic the system is.

Figure 4(a) is the bifurcation diagram of the system (12) with the change of $\alpha_{3}$ when $\sigma=40$; the system (12) first bifurcates at $\alpha_{3}=0.009$ and enters chaos from flip bifurcation. Compared with Figure 3(a), the system (12) enters the unstable state earlier with the increase of demand instability; Figure 4(b) shows the bifurcation diagram of the system (12) with the change of $\alpha_{3}$ when $R_{2}=120$; the first bifurcation of system (12) is delayed at $\alpha_{3}=0.019$ which is in accordance with Figure 2(d). In other words, the stability range of the price adjustment speed of the online retailer will increase with $R_{2}$ increasing.

Conclusion 1. When the customer demand fluctuates greatly, the system is more likely to lose stability and fall into chaos, the two retailers will cut down the product prices to reduce the risk caused by the uncertain market demand, and the increase of risk-aversion level will make the stable range of price adjustment speed of the corresponding retailer larger and make that of the other retailer little.

In the discrete dynamic system, the chaotic attractor is an inseparable set of bounded points composed by many infinitely unstable point sets, which is an important feature of the dissipative dynamical system. When the system is in a stable state, the system's attractor is stable at fixed point; when the system goes into a chaotic state, the system's attractor will occupy a larger space and the structure of the chaotic attractor will be more complicated (shown in Figure 5).

The initial value sensitivity is another important feature of the chaotic system. When the initial value of $p_{3}$ only changes 0.001 with keeping $p_{1}$ and $p_{2}$ unchanged, after multi-iterations, the differences between the two sets of numerical solutions are shown in Figure 6. We can see that, in the beginning iterations, the price values have no difference, but after about 13 time iterations, the difference of price increases greatly. That is, a small difference in the initial value can cause a huge deviation after multiple iterations, which gives us enlightenment that decisionmakers should choose the initial value of their decision variables more prudently.

4.2. 2D Parameter Bifurcation Diagrams. The 2D bifurcation diagram is a more powerful tool for numerical simulation than the 1D bifurcation diagrams. In this paper, we will use $2 \mathrm{D}$ bifurcation diagram to analyze the evolution process of the system's stability region.

Figure 7 presents the parameter plot basins with respect to $\left(\alpha_{1}, \alpha_{2}\right)$ and $\left(\alpha_{2}, \alpha_{3}\right)$ in which red represents stable state, blue 2-period, yellow 4-period, grey chaos, and white 


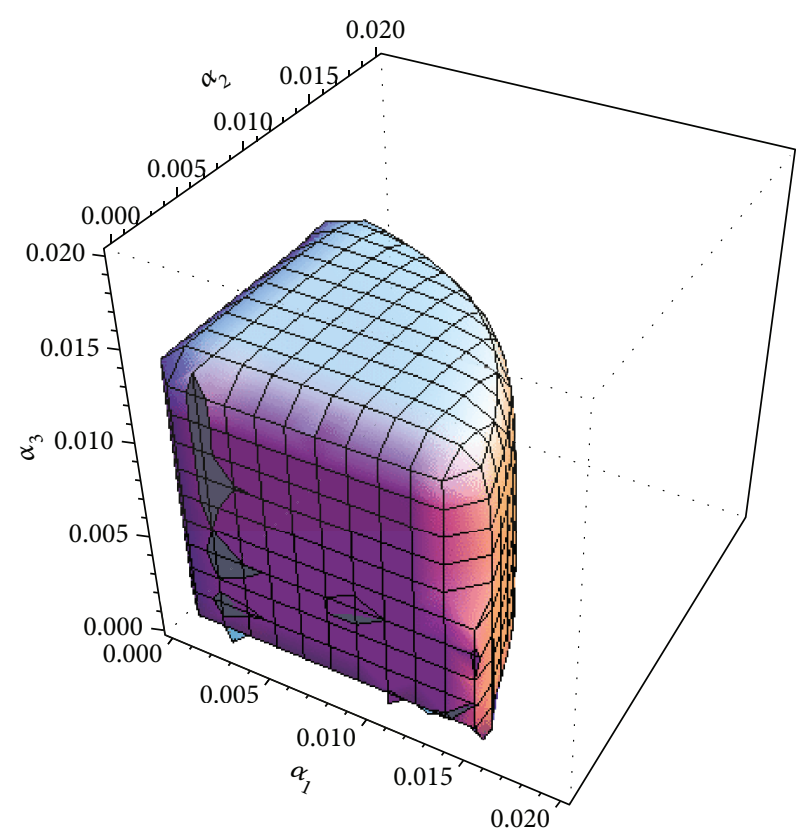

(a) $\sigma=20$

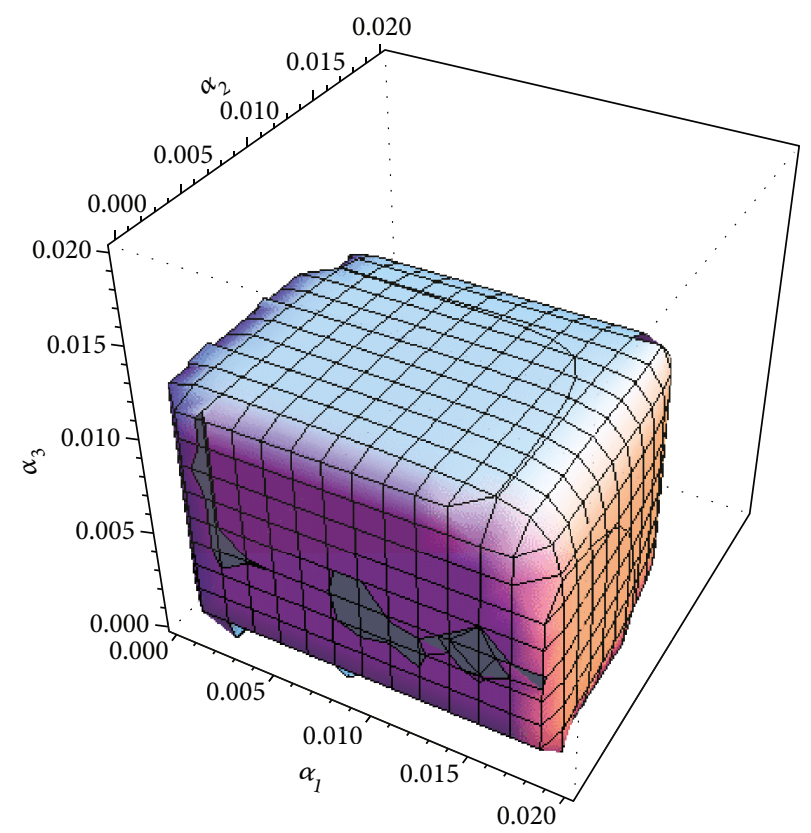

(c) $R_{1}=120$

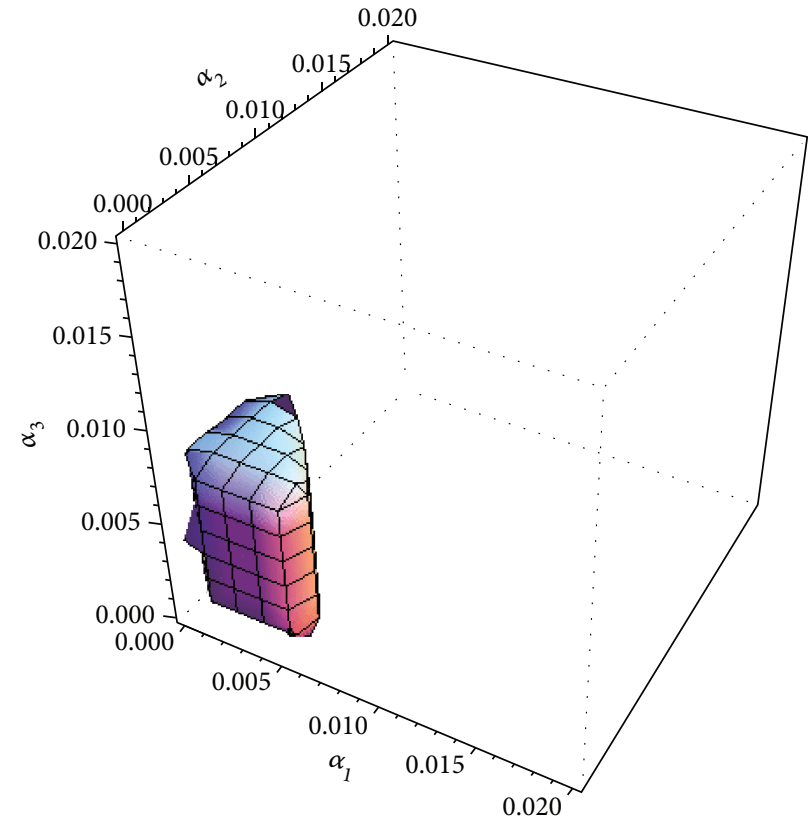

(b) $\sigma=40$

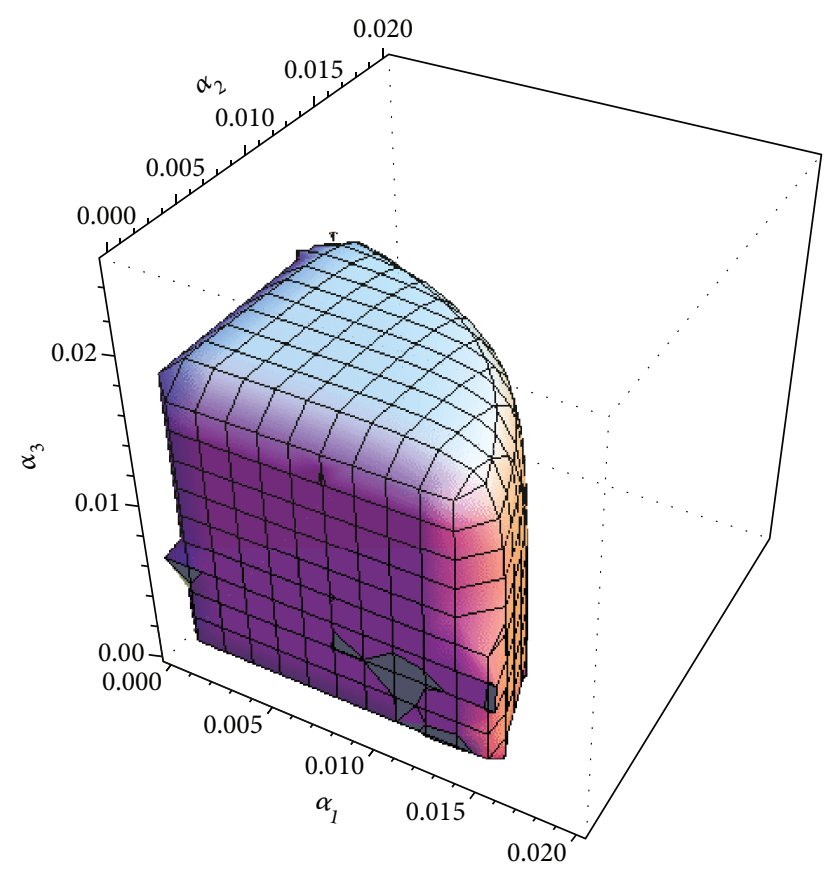

(d) $R_{2}=120$

FIgURE 2: The 3D stable regions of system (12) under different parameter values.

divergence (which means one retailer will withdraw the market). When the price adjustment speed is in the red range, the system (12) will stabilize at the Nash equilibrium point after finite game; when the price adjustment speed increases beyond the stable range, the system (12) will experience flip bifurcation and arrive at the chaotic state.

When $\alpha_{1}=0.005, \alpha_{2}=0.005$, and $\alpha_{3}=0.018$, the system (12) is in a 2-period bifurcation state because of the excessive price adjustment speed of online retailer. Figure 8 shows the $2 \mathrm{D}$ parameter plot basins with respect to $\left(R_{1}, R_{2}\right)$ and $\left(\lambda_{1}, \lambda_{2}\right)$. From Figures $8(\mathrm{a})$ and $8(\mathrm{~b})$, we can see that the higher risk-aversion level and the lower level of fair concern of the online retailer can restore the system (12) to a stable state. When $\alpha_{1}=0.005, \alpha_{2}=0.005$, and $\alpha_{3}=$ 0.022 , the system (12) is in a chaotic state because of the excessive price adjustment speed of online retailer. From Figures 8(c) and 8(d), we can see that the higher risk-aversion level and the lower level of fair concern of the online retailer can only make the system (12) return to the 2-period bifurcation state; the higher level of fair 


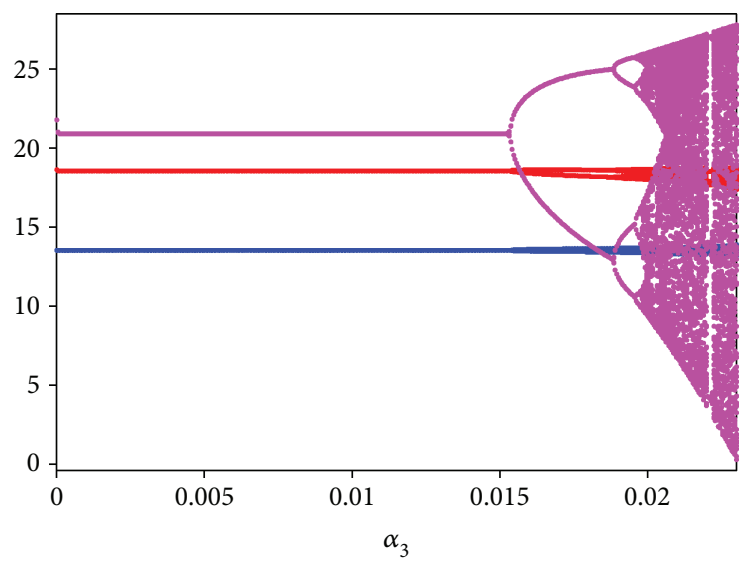

- $\mathrm{p}_{1}$

- $\mathrm{p}_{2}$

- $\mathrm{p}_{3}$

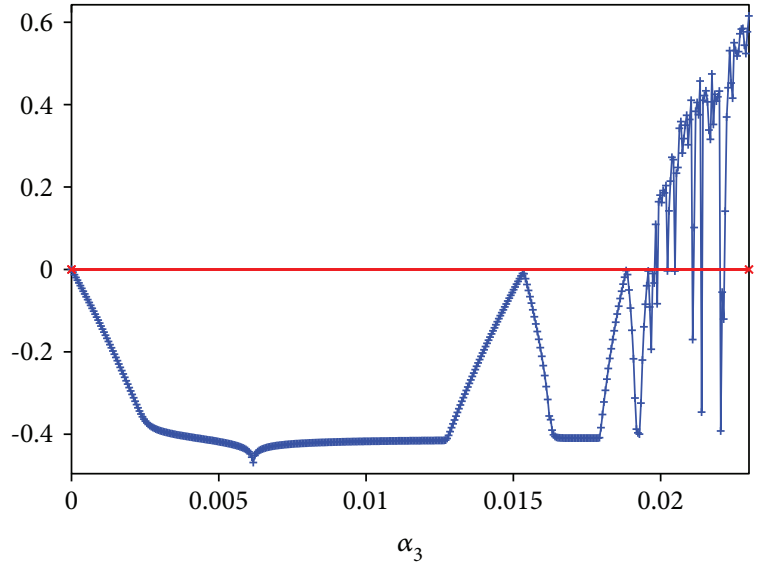

(b) LLE diagram

Figure 3: The evolution process of system (12) when $\alpha_{1}=\alpha_{2}=0.005$.

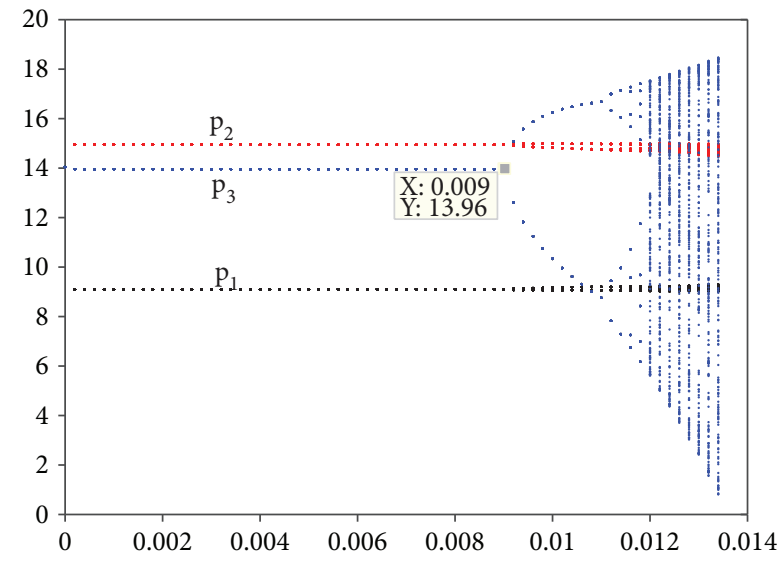

(a) $\sigma=40$

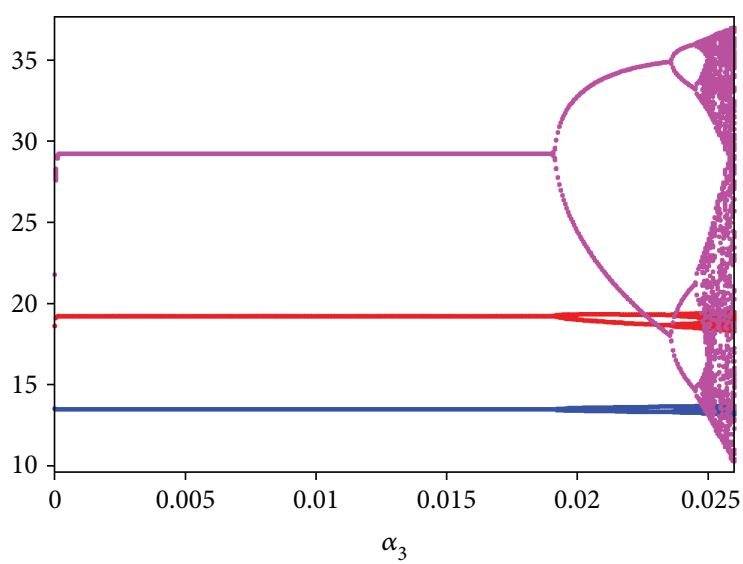

- $\mathrm{p}_{1}$

- $\mathrm{p}_{2}$

- $\mathrm{p}_{3}$

(b) $R_{2}=120$

FIGURE 4: The evolution process of system (12) with different parameter values.

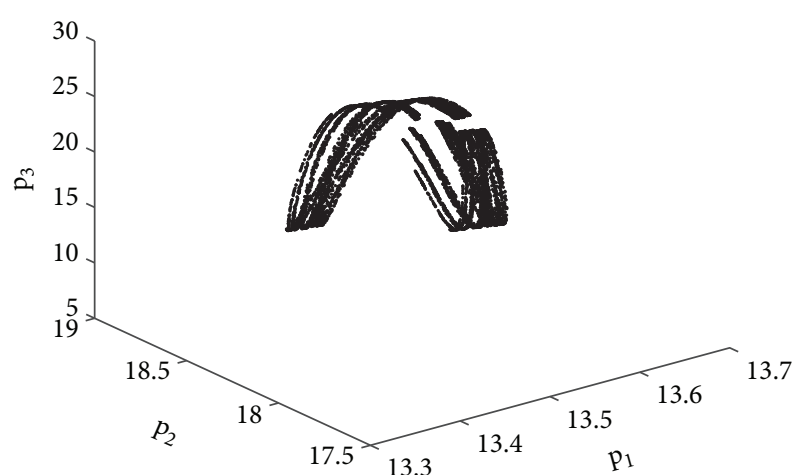

FIgURE 5: The chaotic attractor when $\alpha_{1}=\alpha_{2}=0.005$ and $\alpha_{3}=$ 0.0206 . concern of online retailer is more likely to make the system (12) unstable or even into chaos.

Conclusion 2. Adjusting the risk-aversion level or the fairness concern level of the online retailer can make the system (12) be in a stable state or delay the occurrence of system instability.

4.3. The Influence of Parameter Changes on the Utilities of the Two Retailers. From the analysis above, we can find that, with the change of parameter values, the instability of system (12) will increase obviously which can cause the market to be complex; it is complicated for the decision-maker to make a price decision. So we suspect that the utilities of two retailers will also be influenced. This section mainly analyzes the 


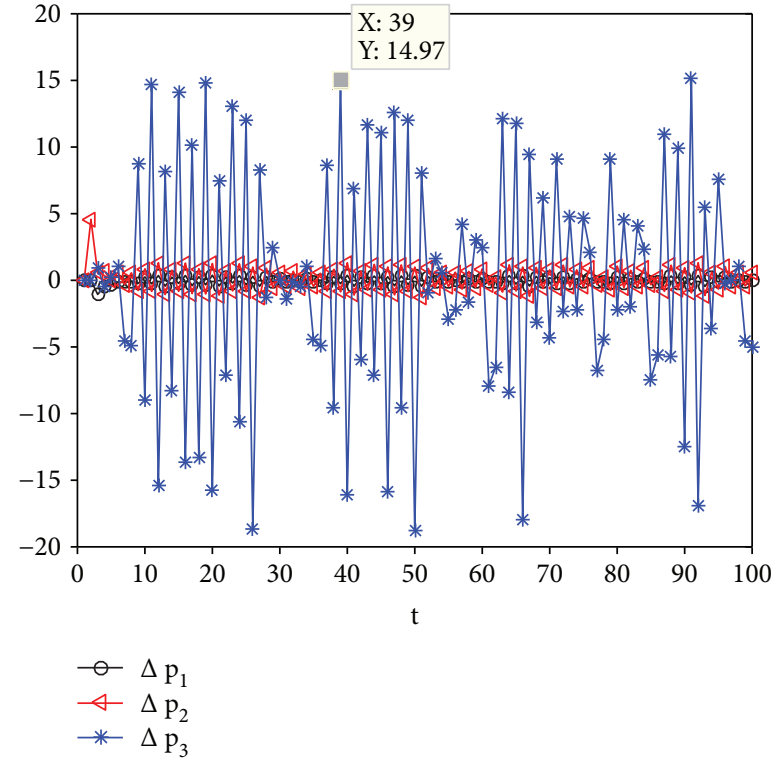

FIgURE 6: The sensitivity to initial value when $\left(p_{1}, p_{2}, p_{3}\right)=(18.52$, $22.35,21.78)$ and $(18.52,22.35,21.781)$.

influences of price adjustment speed, demand fluctuation, and risk-aversion level on the utilities of the two retailers.

Figure 9 is the evolution diagrams of the utilities of two retailers with the increase of $\alpha_{3}$; when $\alpha_{3}<0.0156$, the utilities of the two retailers are in a stable state; when $\alpha_{3}>$ 0.0156 , the utilities of the two retailers go into chaos through the flip bifurcation which is in accordance with Figure 3(a). Figure 9(b) shows the evolution diagram of the average utilities of two retailers with the increase of $\alpha_{3}$; we can see that the average utility of online retailer decreases and the average utility of dual-channel retailer increases.

Figures 10 and 11 describe the impact of risk-aversion level and fairness concern level on the utilities of the two retailers when the system (12) is in a stable state. The utilities of the dual-channel retailer increase and those of the online retailer decrease with $R_{1}$ increasing; the utilities of the dualchannel retailer decrease and those of the online retailer increase with $R_{2}$ increasing. The utility of the online retailer increases and the utility of the dual-channel retailer decreases with the increase of $\lambda_{1}$ and $\lambda_{2}$, respectively, so the dualchannel retailer should not pay too much attention to the comparison of online profit with that of the online retailer.

Figure 12 shows the change process of the two retailers' utilities under the condition of two-parameter change. Figures 12(a) and 12(b) indicate the utility evolution of the two retailers with the change of risk-aversion level and fair concern level when the system (12) is in the stable state and chaotic state. It is found that when the system (12) is in a stable state, the utilities of the two retailers increase with the increase of $\left(R_{1}, \lambda_{1}\right)$ and $\left(R_{2}, \lambda_{2}\right)$. Therefore, when the system (12) is in a stable state, the two retailers should maintain a high level of risk-aversion and fair concern level. The utility change process of the two retailers is shown in Figures 12(c) and 12(d), respectively, when the system (12) is in a chaotic state. When $R_{i}$ and $\lambda_{i}$ are relatively small, the utilities of the two retailers are in the 2-periond bifurcation state; when $R_{i}$ and $\lambda_{i}$ are bigger, the utilities of the two retailers fluctuate fiercely and even appear negative which is not conducive for the two retailers to achieve the goal of maximum utility. The market competitors should control the parameters in a certain range to avoid the market in chaos.

Conclusion 3. When the system (12) is in a stable state, increasing the risk-aversion level and fairness concern level of the two retailers can obtain higher utilities; when the system (12) is in chaos, the utilities of the two retailers will fluctuate sharply or even lose money. For the sake of system stability, the two retailers should control the parameters in a certain range to avoid the market in chaos.

\section{Chaos Control}

When the market is in a chaotic state, the competition becomes disordered and unpredictable and the utilities of competitors fluctuate fiercely, which is not conducive to market operation management and long-term decision-making.

As shown above, once the chaos occurs in a complex and dynamic supply chain, the two retailers will find it is not easy to maintain the market in equilibrium state. There are so many factors which affect the stability of the system, such as the price adjustment speed, risk-aversion behavior, fair concern behavior, and the ability to collect information. When the system loses the stable state, the system will be out of order and unpredictable. In order to achieve business objectives, the efficient measures should be taken to make the system return to a stable state.

The state feedback control method is widely applied to the chaos control of supply chain system $[35,36]$. In this paper, we use the state feedback control method to control the chaotic state of the dual-channel supply chain system.

Suppose that the initial system is $p_{i}(t+1)=f_{i}\left(p_{1}(t)\right.$, $\left.p_{2}(t), p_{3}(t)\right) \quad(i=1,2,3)$, the control system is expressed as follows:

$p_{i}(t+1)=(1-v) f_{i}\left(p_{1}(t), p_{2}(t), p_{3}(t)\right)+v p_{i}(t) \quad(i=1,2,3)$,

where $v$ is the control parameter which can express the government's control over the price adjustment speed or the learning adaptability of market competitors. When $v=0$, the control system degenerates into the initial system.

From Figure 13, we can see that the system (20) gradually returns to a stable state from the chaotic state. When $v>0.31$, the system (20) is controlled in a stable state and stabilizes at the Nash equilibrium point.

The two retailers hope the market is stable because it is easier for them to make decisions and pursue maximum utilities in a stable state. However, the dual-channel supply chain system is a very complex system; the changes of decision variables and parameters will make the system enter the chaotic state from the stable state. Therefore, the two retailers need to jointly formulate measures to 


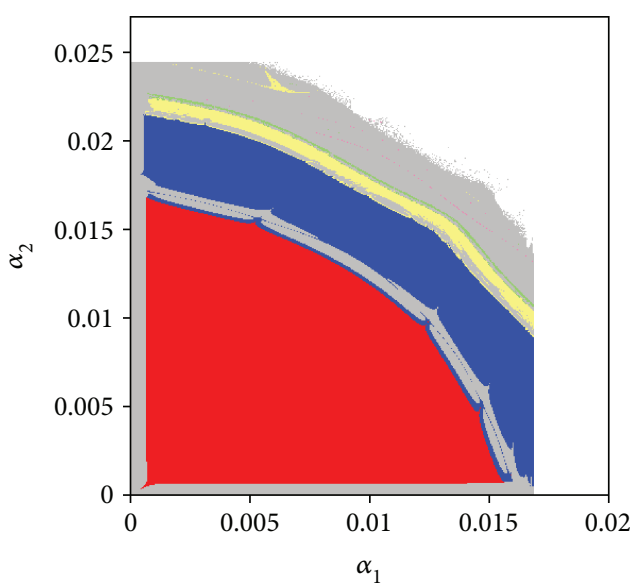

(a) The plane of $\alpha_{1}$ and $\alpha_{2}$

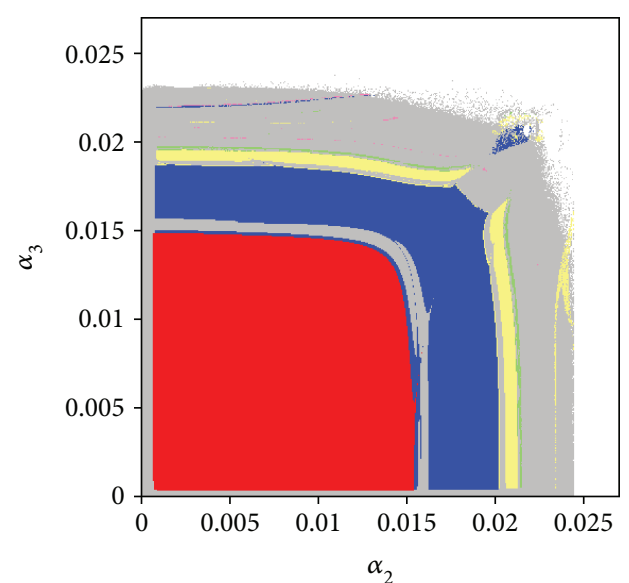

(b) The plane of $\alpha_{2}$ and $\alpha_{3}$

FIGURE 7: The 2D bifurcation diagram of system (12).

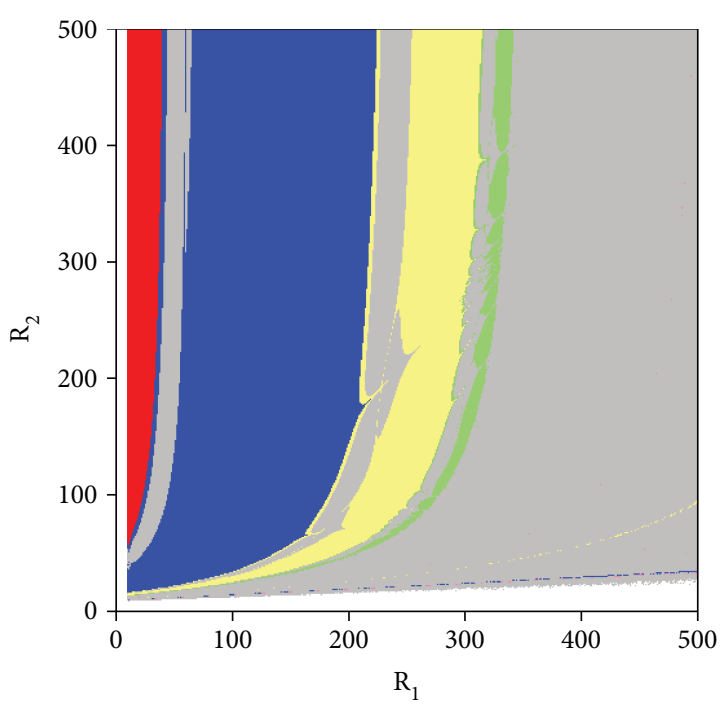

(a) The plane of $R_{1}$ and $R_{2}$ with $\alpha_{3}=0.018$

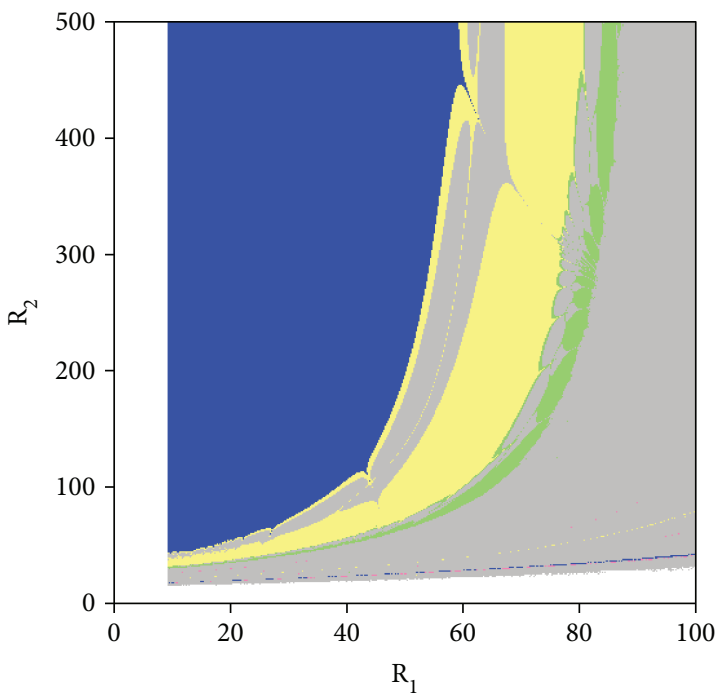

(c) The plane of $R_{1}$ and $R_{2}$ with $\alpha_{3}=0.022$

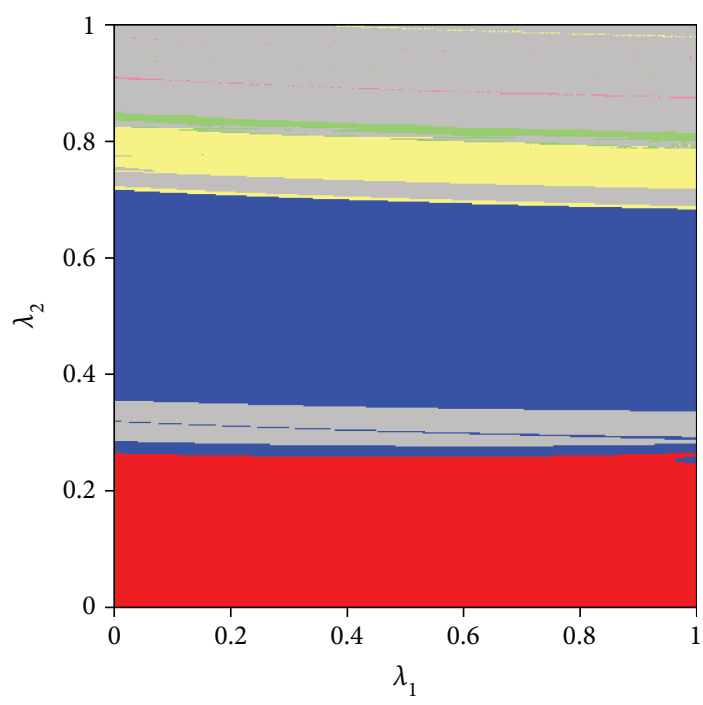

(b) The plane of $\lambda_{1}$ and $\lambda_{2}$ with $\alpha_{3}=0.018$

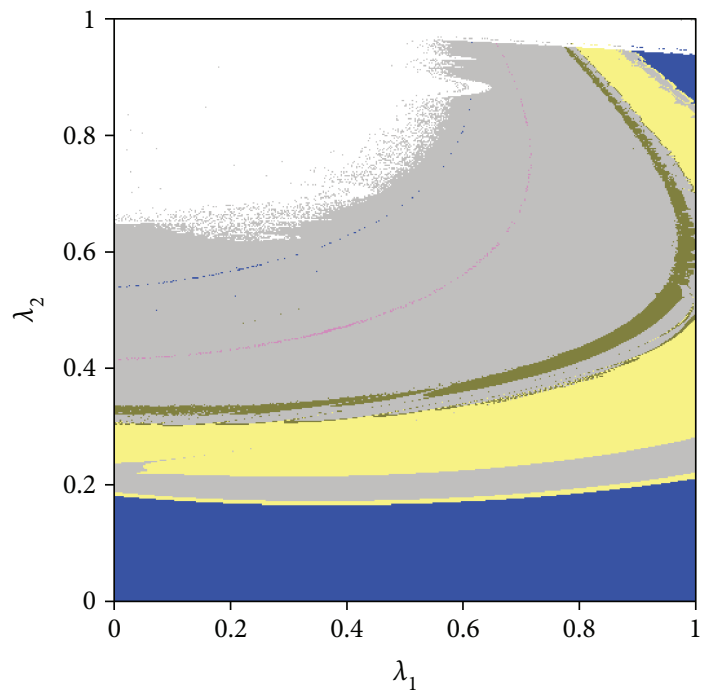

(d) The plane of $\lambda_{1}$ and $\lambda_{2}$ with $\alpha_{3}=0.022$

FIgURE 8: The 2D bifurcation diagram of system (12). 


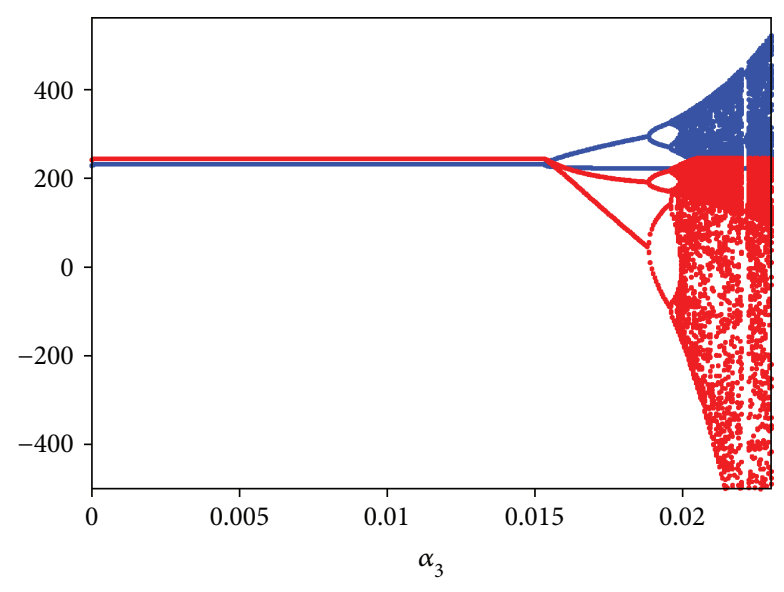

- $\pi_{1}$

(a) Bifurcation diagram of utility

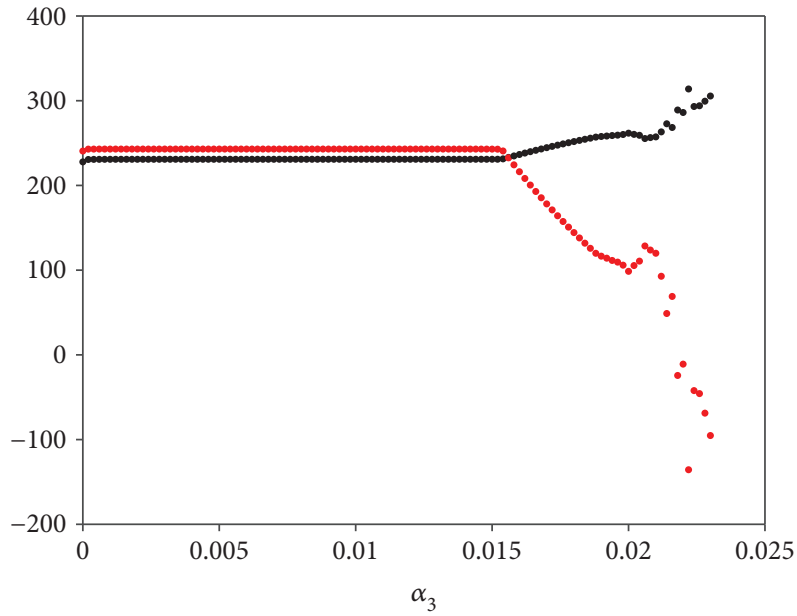

- $\pi_{1}$

- $\pi_{2}$

FIGURE 9: The evolution process of the two retailers' utilities with $\alpha_{3}$ changing.

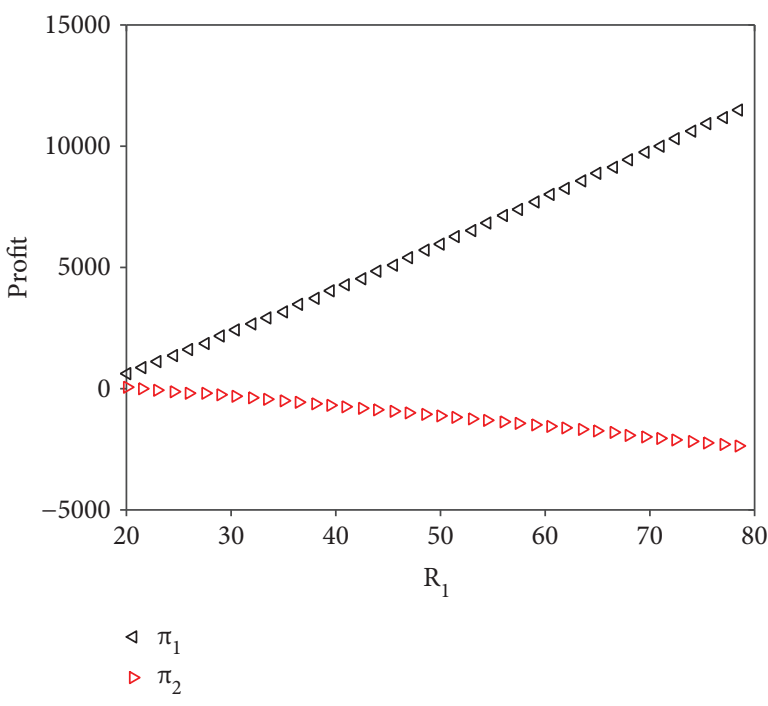

(a) $R_{1}$

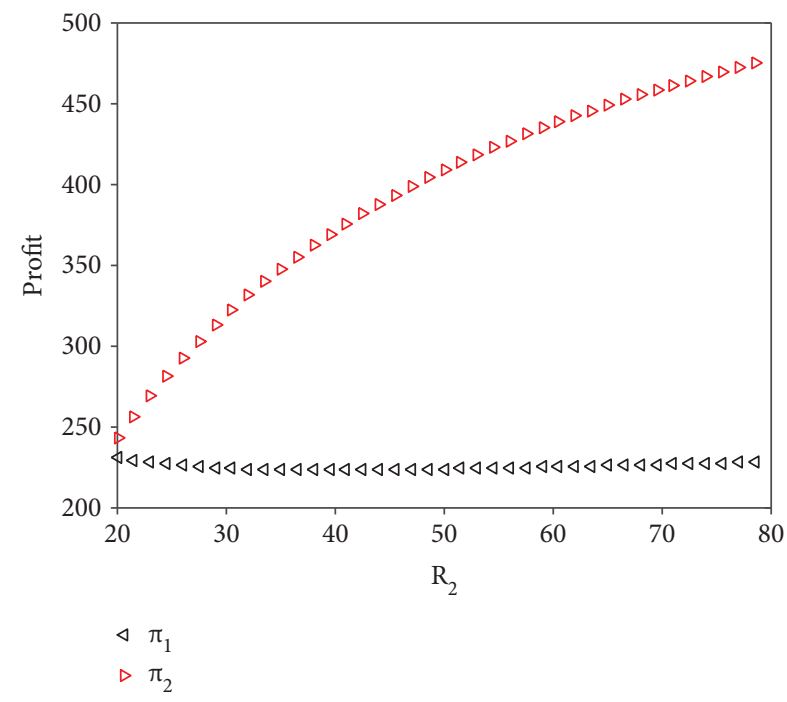

(b) $R_{2}$

Figure 10: The influence of risk-aversion level on the utilities of the two retailers.

delay or eliminate chaos, so as to achieve market stability and development.

\section{Conclusions}

Considering the risk-averse behavior and fairness concern behavior of the two retailers, this paper constructs a dynamic price game model of a dual-channel supply chain. Based on game theory and nonlinear dynamics theory, the influences of parameter changes on the stability of the model and the retailers' utilities are studied. The conclusions obtained are as follows:

(1) When the customer demand fluctuates greatly, the system is more likely to lose stability and fall into chaos and the two retailers will cut down the product's price to reduce the risk caused by the uncertain market demand. Adjusting the risk-aversion level or the fairness concern level of the online retailer can make the system (12) be in a stable state or delay the occurrence of system instability

(2) As the price adjustment speed increases, the system will enter chaos through flip bifurcation; when the system is in a chaotic state, the average utility of online retailer decreases and the average utility of dual-channel retailer increases.

(3) When the system is in a stable state, increasing the risk-aversion level and fairness concern level of the 


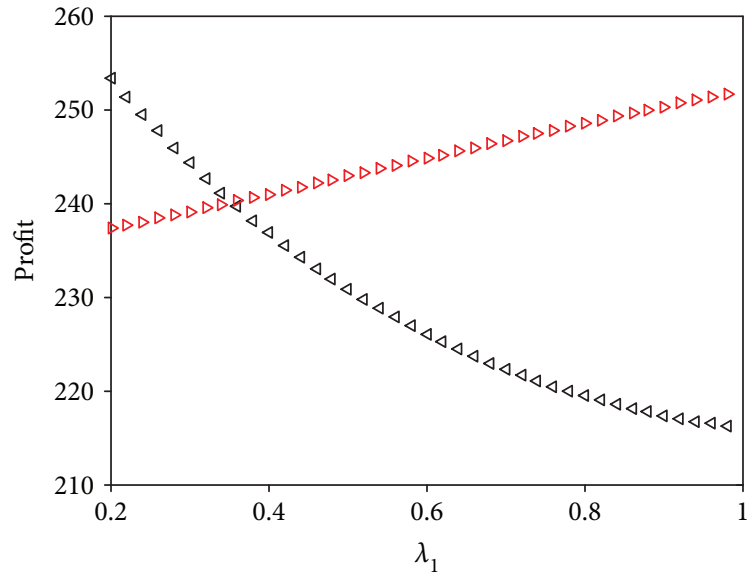

$$
\triangleleft \pi_{1}
$$$$
\triangleright \pi_{2}
$$

(a) $\lambda_{1}$

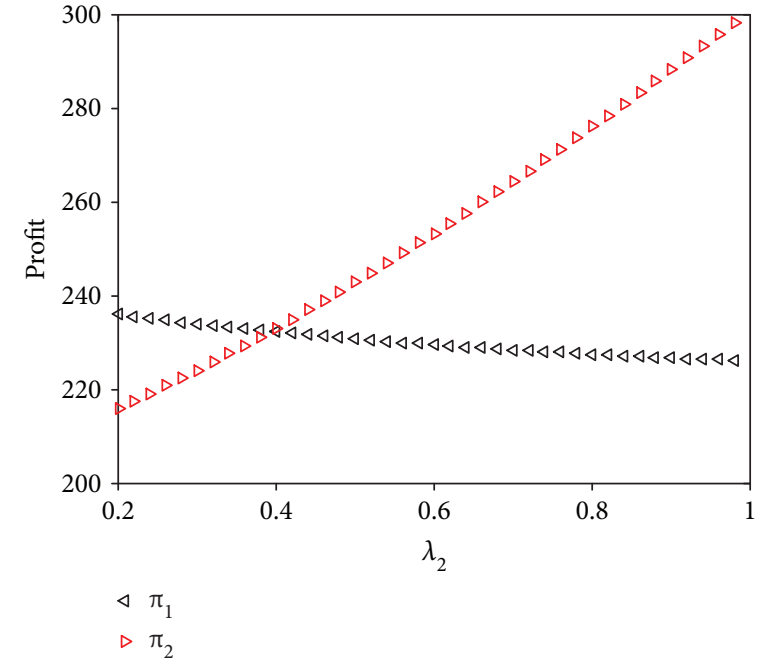

(b) $\lambda_{2}$

Figure 11: The influence of fairness concern level on the utilities of the two retailers.

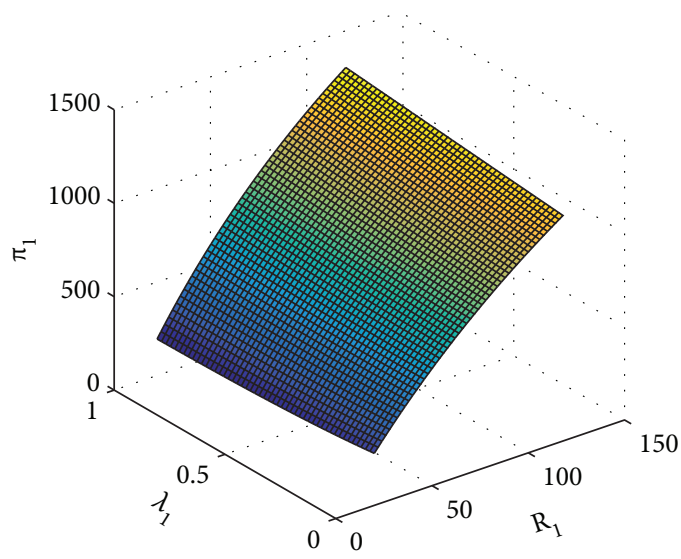

(a) $R_{1}, \lambda_{1}$

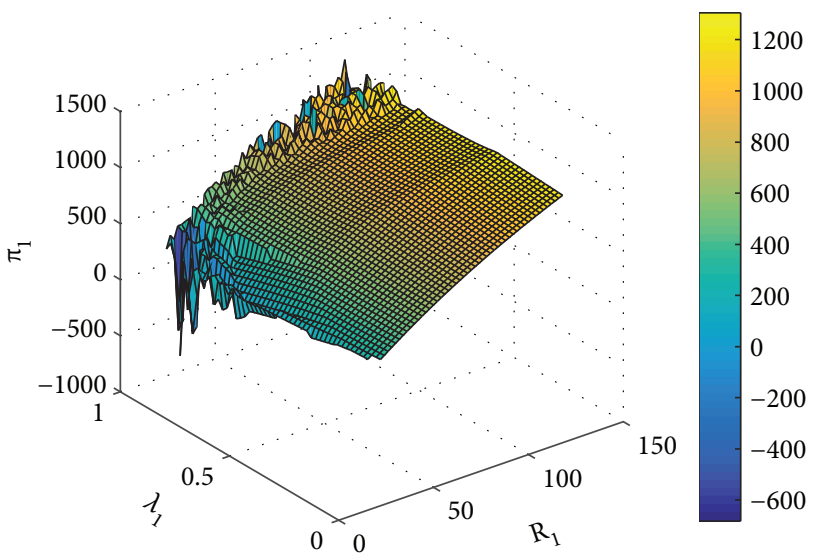

(c) $R_{1}, \lambda_{1}$

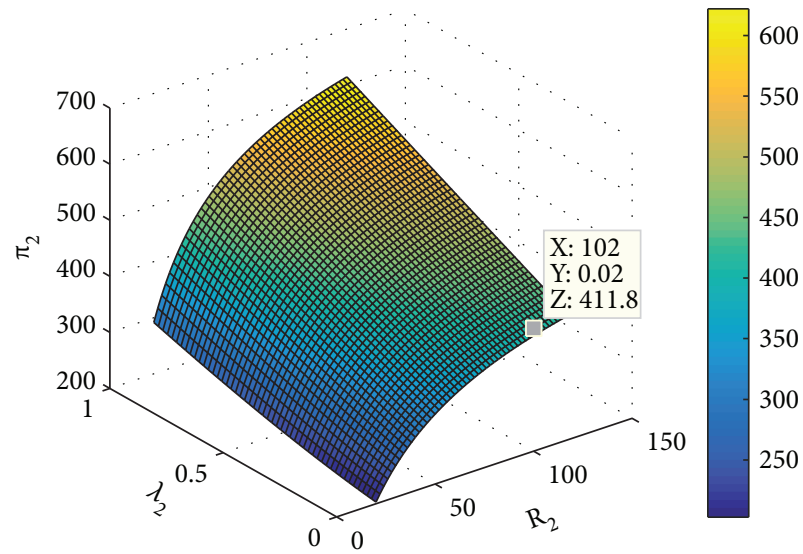

(b) $R_{2}, \lambda_{2}$

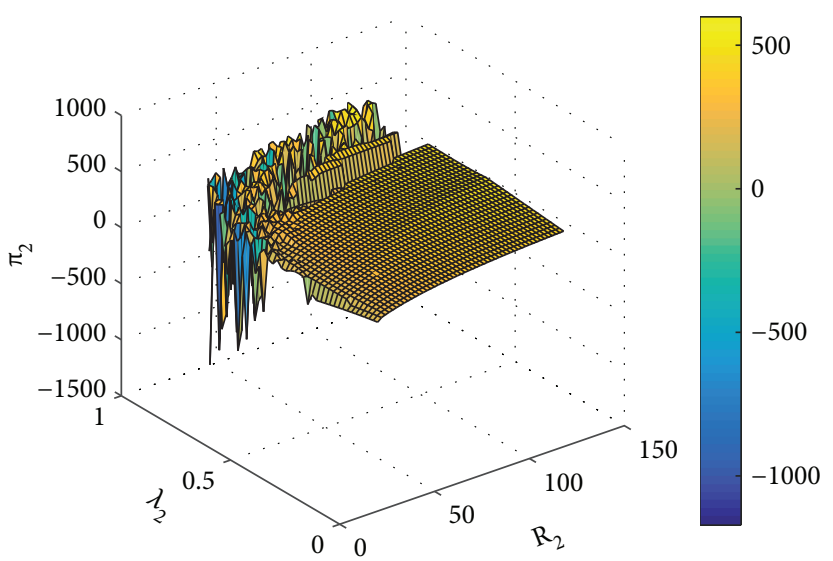

(d) $R_{2}, \lambda_{2}$

Figure 12: The influences of $R_{i}$ and $\lambda_{i}$ on utilities of the two retailers.

two retailers can obtain higher utilities; when the system is in chaos, the utilities of the two retailers will fluctuate sharply or even lose money. For the sake of system stability, the two retailers should control the parameters in a certain range to avoid the market in chaos 


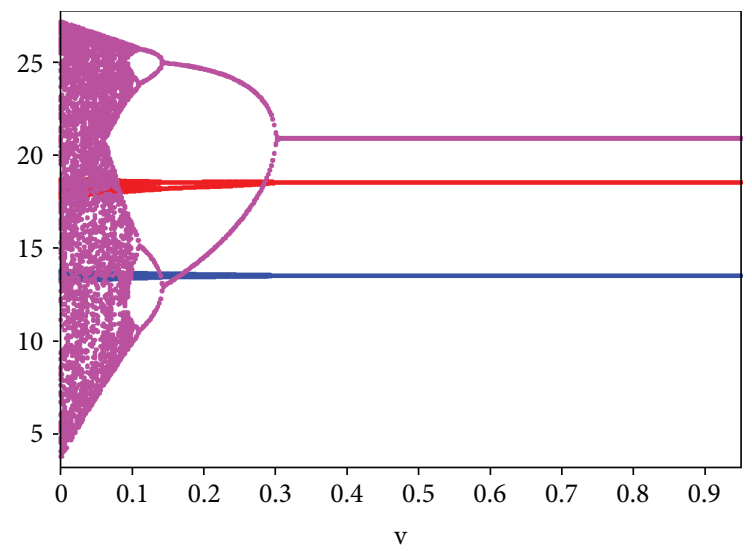

- $\mathrm{p}_{1}$

- $\mathrm{p}_{2}$

$\mathrm{p}_{3}$

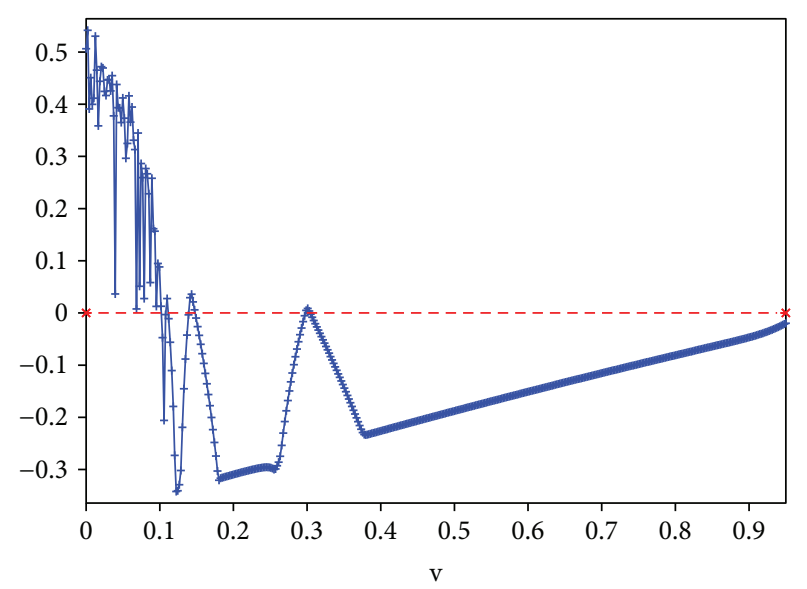

(b)

FIGURE 13: The influence of $v$ on the price evolution process of the system (20).

(4) Using the state feedback control method, the system can return to a stable state from chaos by selecting appropriate control parameters.

\section{Appendix}

\section{The Equilibrium Solutions of the System (12)}

$$
\begin{aligned}
& E_{2}=\left(0,0, \frac{R_{2}\left(c\left(b \lambda_{2}+b+2 \gamma k \lambda_{2}\right)-a(\theta-1)\left(\lambda_{2}+1\right)\right)+c(\theta-1)^{2} \sigma^{2}}{2 b\left(\lambda_{2}+1\right) R_{2}+(\theta-1)^{2} \sigma^{2}}\right) \\
& E_{3}=\left(0, \frac{c(-1+\theta)^{2} \sigma^{2}-a R_{1}(-1+\theta)\left(1+\lambda_{1}\right)+c R_{1}\left(b-k+b \lambda_{1}+k \lambda_{1}\right)}{(-1+\theta)^{2} \sigma^{2}+2 b\left(1+\lambda_{1}\right) R_{1}}, 0\right) \text {, } \\
& E_{4}=\left(\frac{c \theta^{2} \sigma^{2}+R_{1}(b c-c k+a \theta)}{\theta^{2} \sigma^{2}+2 b R_{1}}, 0,0\right) \\
& E_{5}=\left(0,-\frac{k\left(-a(\theta-1)\left(\lambda_{2}+1\right)+c\left(b \lambda_{2}+b+2 \gamma k \lambda_{2}\right)+\left(c(\theta-1)^{2} \sigma^{2} / R_{2}\right)\right)+\left(-2 b\left(\lambda_{2}+1\right)-(\theta-1)^{2} \sigma^{2} / R_{2}\right)\left(a(\theta-1)\left(\lambda_{1}+1\right)-c\left(b \lambda_{1}+b+k \lambda_{1}-k\right)-c(\theta-1)^{2} \sigma^{2} / R_{1}\right)}{k^{2}\left(-\gamma \lambda_{2}+\lambda_{2}+1\right)-\left(2 b\left(\lambda_{1}+1\right)+\left((\theta-1)^{2} \sigma^{2} / R_{1}\right)\right)\left(2 b\left(\lambda_{2}+1\right)+\left((\theta-1)^{2} \sigma^{2} / R_{2}\right)\right)},\right. \\
& \frac{R_{1} R_{2}\left(c\left(2 b^{2}\left(\lambda_{1}+1\right)\left(\lambda_{2}+1\right)+b k\left(\lambda_{1}+1\right)\left(3 \gamma \lambda_{2}+\lambda_{2}+1\right)-k^{2} \lambda_{1}-1\right)\left((\gamma-1) \lambda_{2}-1\right)\right)-a R_{1}(\theta-1)\left(\lambda_{1}+1\right)\left(2 b\left(\lambda_{2}+1\right)+k\left(-\gamma \lambda_{2}+\lambda_{2}+1\right)\right)+2 b c \sigma^{2}(\theta-1)^{2}\left(\lambda_{1}+1\right)}{R_{1} R_{2}\left(4 b^{2}\left(\lambda_{1}+1\right)\left(\lambda_{2}+1\right)+k^{2}\left((\gamma-1) \lambda_{2}-1\right)\right)+2 b R_{1 \sigma^{2}}(\theta-1)^{2}\left(\lambda_{1}+1\right)+\sigma^{2}(\theta-1)^{2}\left(2 b\left(\lambda_{2}+1\right) R_{2}+(\theta-1)^{2} \sigma^{2}\right)} \\
& \left.+\frac{\sigma^{2}(\theta-1)^{2}\left(c R_{2}\left(b \lambda_{2}+b+\gamma k \lambda_{2}+k \lambda_{2}+k\right)-a R_{2}(\theta-1)\left(\lambda_{2}+1\right)+c(\theta-1)^{2} \sigma^{2}\right)}{R_{1} R_{2}\left(4 b^{2}\left(\lambda_{1}+1\right)\left(\lambda_{2}+1\right)+k^{2}\left((\gamma-1) \lambda_{2}-1\right)\right)+2 b R_{1 \sigma^{2}}(\theta-1)^{2}\left(\lambda_{1}+1\right)+\sigma^{2}(\theta-1)^{2}\left(2 b\left(\lambda_{2}+1\right) R_{2}+(\theta-1)^{2} \sigma^{2}\right)}\right), \\
& E_{6}=\left(-\frac{\left(\left(2 b\left(\lambda_{1}+1\right) R_{1}+(\theta-1)^{2} \sigma^{2}\right)\left(R_{1}(a \theta+b c-c k)+c \theta^{2} \sigma^{2}\right) / R_{1}^{2}\right)+k\left(\lambda_{1}+2\right)\left(-a(\theta-1)\left(\lambda_{1}+1\right)+b c\left(\lambda_{1}+1\right)+c k\left(\lambda_{1}-1\right)+\left(c(\theta-1)^{2} \sigma^{2} / R_{1}\right)\right)}{k^{2}\left(\lambda_{1}+2\right)^{2}-\left(2 b R_{1}+\theta^{2} \sigma^{2}\right)\left(2 b\left(\lambda_{1}+1\right) R_{1}+(\theta-1)^{2} \sigma^{2}\right) / R_{1}^{2}},\right. \\
& \left.\frac{a R_{1}^{2}\left(\theta k\left(\lambda_{1}+2\right)-2 b(\theta-1)\left(\lambda_{1}+1\right)\right)+c R_{1}^{2}\left(2 b^{2}\left(\lambda_{1}+1\right)+3 b k \lambda_{1}-k^{2}\left(\lambda_{1}+2\right)\right)+R_{1} \sigma^{2}\left(\theta^{2}\left(c k\left(2 \lambda_{1}+1\right)-a(\theta-1)\left(\lambda_{1}+1\right)\right)+b c\left(\theta^{2}\left(\lambda_{1}+3\right)-4 \theta+2\right)\right)+c(\theta-1)^{2} \theta^{2} \sigma^{4}}{R_{1}^{2}\left(4 b^{2}\left(\lambda_{1}+1\right)-k^{2}\left(\lambda_{1}+2\right)^{2}\right)+2 b R_{1} \sigma^{2}\left(\theta^{2}\left(\lambda_{1}+2\right)-2 \theta+1\right)+(\theta-1)^{2} \theta^{2} \sigma^{4}}, 0\right), \\
& E_{7}=\left(-\frac{\left(k-k \lambda_{1}\right)\left(-a(\theta-1)\left(\lambda_{2}+1\right)+c\left(b \lambda_{2}+b+2 \gamma k \lambda_{2}\right)+\left(c(\theta-1)^{2} \sigma^{2} / R_{2}\right)\right)+\left(-2 b\left(\lambda_{2}+1\right)-(\theta-1)^{2} \sigma^{2} / R_{2}\right)\left(-a \theta-b c+c k-c \theta^{2} \sigma^{2} / R_{1}\right)}{k\left(-\gamma \lambda_{2}+\lambda_{2}+1\right)\left(k-k \lambda_{1}\right)-\left(-2 b-\theta^{2} \sigma^{2} / R_{1}\right)\left(-2 b\left(\lambda_{2}+1\right)-(\theta-1)^{2} \sigma^{2} / R_{2}\right)}, 0,\right. \\
& \frac{R_{1} R_{2}\left(a \theta k\left(-\gamma \lambda_{2}+\lambda_{2}+1\right)-2 a b(\theta-1)\left(\lambda_{2}+1\right)+2 c b^{2}\left(\lambda_{2}+1\right)+b c k\left(3 \gamma \lambda_{2}+\lambda_{2}+1\right)+c k^{2}\left(\lambda_{2}(\gamma-1)-1\right)\right)+2 b c \sigma^{2 R_{1}}(\theta-1)^{2}+c \sigma^{2}(\theta-1)^{2}}{R_{1}\left(R_{2}\left(4 b^{2}\left(\lambda_{2}+1\right)-k^{2}\left(\lambda_{1}-1\right)\left((\gamma-1) \lambda_{2}-1\right)\right)+2 b(\theta-1)^{2} \sigma^{2}\right)+\theta^{2} \sigma^{2}\left(2 b\left(\lambda_{2}+1\right) R_{2}+(\theta-1)^{2} \sigma^{2}\right)} \\
& \left.+\frac{\theta^{2} \sigma^{2}\left(R_{2} \theta^{2} \sigma^{2}\left(c\left(b \lambda_{2}+b+\gamma k \lambda_{2}+k \lambda_{2}+k\right)-a(\theta-1)\left(\lambda_{2}+1\right)\right)+c \theta^{2} \sigma^{4}(\theta-1)^{2}\right)}{R_{1}\left(R_{2}\left(4 b^{2}\left(\lambda_{2}+1\right)-k^{2}\left(\lambda_{1}-1\right)\left((\gamma-1) \lambda_{2}-1\right)\right)+2 b(\theta-1)^{2} \sigma^{2}\right)+\theta^{2} \sigma^{2}\left(2 b\left(\lambda_{2}+1\right) R_{2}+(\theta-1)^{2} \sigma^{2}\right)}\right) .
\end{aligned}
$$




\section{Data Availability}

There are no data used to support this study.

\section{Conflicts of Interest}

The authors declare that they have no conflicts of interest.

\section{Acknowledgments}

The research was supported by Henan Province Soft Science Research Plan Project (no. 182400410054), Henan Provincial Government Decision Research Tendering Project (no. 2018B019), and Henan Provincial Social Science Planning Decision Consultation Project (no. 2018JC05).

\section{References}

[1] W. Y. K. Chiang, D. Chhajed, and J. D. Hess, "Direct marketing, indirect profits: a strategic analysis of dual-channel supply-chain design," Management Science, vol. 49, no. 1, pp. 1-20, 2003.

[2] X. Gan, S. P. Sethi, and H. Yan, "Channel coordination with a risk-neutral supplier and a downside-risk-averse retailer," Production and Operations Management, vol. 14, no. 1, pp. 80-89, 2005.

[3] C. Y. Yu, X. N. Zhao, Y. D. Peng, and D. H. Pan, "Study of supply chains optimization and coordination model based on conditional value-at-risk," Chinese Journal of Management Science, vol. 15, no. 3, pp. 31-39, 2007.

[4] P. Qinghua, "Coordinating a two-level supply chain with riskaverse preferences based on revenue-sharing contract," in 2008 27th Chinese Control Conference, pp. 1094-1099, Kunming, China, 2008.

[5] J. Wu, S. Wang, X. Chao, C. T. Ng, and T. C. E. Cheng, "Impact of risk aversion on optimal decisions in supply contracts," International Journal of Production Economics, vol. 128, no. 2, pp. 569-576, 2010.

[6] S. Li and Z. Zhang, "Pricing strategy in risk-averse dualchannel supply chain," Advances in Information Sciences and Service Sciences, vol. 4, no. 5, pp. 78-87, 2012.

[7] B. Li, P. Chen, Q. Li, and W. Wang, "Dual-channel supply chain pricing decisions with a risk-averse retailer," International Journal of Production Research, vol. 52, no. 23, pp. 7132-7147, 2014.

[8] H. Golpîra, "Supply chain network design optimization with risk-averse retailer," International Journal of Information Systems and Supply Chain Management, vol. 10, no. 1, pp. 16-28, 2017.

[9] M. R. Amin-Naseri and M. A. Khojasteh, "Price competition between two leader-follower supply chains with risk-averse retailers under demand uncertainty," International Journal of Advanced Manufacturing Technology, vol. 79, no. 1-4, pp. 377-393, 2015.

[10] J. Du, P. Dou, and L. Zhao, "The impact of retailer's risk aversion and fairness preference on green supply chain operation," Journal of Industrial Technological \& Economics, no. 7, pp. 3-9, 2017.

[11] E. Fehr and K. M. Schmidt, "A theory of fairness, competition, and cooperation," Quarterly Journal of Economics, vol. 114, no. 3, pp. 817-868, 1999.
[12] T. H. Cui, J. S. Raju, and Z. J. Zhang, "Fairness and channel coordination," Management Science, vol. 53, no. 8, pp. 13031314, 2007.

[13] S. Du, C. Du, L. Liang, and T. Z. Liu, "Supply chain coordination considering fairness concerns," Journal of Management Sciences in China, vol. 13, 2010.

[14] K. Zhang, S. Hou, and G. Zhou, "Pricing strategy in the closedloop supply chain with fairness concerns," Journal of Systems \& Management, vol. 6, pp. 841-849, 2013.

[15] V. Pavlov and E. Katok, "Fairness and coordination failures in supply chain contracts," SSRN Electronic Journal, 2011.

[16] Q. H. Li and B. Li, "Dual-channel supply chain equilibrium problems regarding retail services and fairness concerns," Applied Mathematical Modelling, vol. 40, no. 15-16, pp. 7349-7367, 2016.

[17] F. Zhang and J. Ma, "Research on the complex features about a dual-channel supply chain with a fair caring retailer," Communications in Nonlinear Science and Numerical Simulation, vol. 30, no. 1-3, pp. 151-167, 2016.

[18] H. Yang and X. Sun, "A study on pricing decision of supply chain based on fairness concern," in Proceedings of the International Conference on Advances in Materials, Machinery, Electronics (AMME 2017), p. 080002, Wuhan, China, 2017.

[19] B. Niu, Q. Cui, and J. Zhang, "Impact of channel power and fairness concern on supplier's market entry decision," Journal of the Operational Research Society, vol. 68, no. 12, pp. 1570$1581,2017$.

[20] B. Li, P. W. Hou, and Q. H. Li, "Cooperative advertising in a dual-channel supply chain with a fairness concern of the manufacturer," IMA Journal of Management Mathematics, vol. 28, no. 2, pp. 259-277, 2017.

[21] B. Li, P. Hou, and Q. Li, "Cooperative advertising strategy in a dual channel supply chain with members' fairness concern," Journal of Systems \& Management, vol. 26, no. 3, pp. 562$568,2017$.

[22] J. X. Chen and Y. W. Zhou, "Pricing and ordering strategies of supply chain with fairness-concerned retailer and demand depending on the retail price," Operations Research and Management Science, vol. 26, no. 8, pp. 92-98, 2017.

[23] T. Nie, B. He, and S. Du, "Supply chain operations considering fairness concerns with bargaining disagreement point," Journal of Management Sciences in China, vol. 20, no. 10, pp. 92 102, 2017.

[24] C. Zhang, P. Xing, and J. Zhu, "Research on logistic service supply chain quality supervision and cooperation concerning fairness preference," Journal of Industrial Engineering and Engineering Management, vol. 31, no. 4, pp. 164-170, 2017.

[25] T. Puu, "On the stability of Cournot equilibrium when the number of competitors increases," Journal of Economic Behavior \& Organization, vol. 66, no. 3-4, pp. 445-456, 2008.

[26] Y. Lu, "Research on chaos complexity of output game with different decision rules," Journal of Systems Engineering, vol. 27, no. 2, pp. 208-213, 2012.

[27] F. Liu, Y. Li, and H. Wang, "Four oligarchs price game model and its complex characteristics with nonlinear demand," Journal of Systems Engineering, vol. 31, no. 6, pp. 719-728, 2016.

[28] F. Si and J. Ma, "Complex dynamics in a triopoly game with multiple delays in the competition of green product level," International Journal of Bifurcation and Chaos, vol. 28, no. 2, article 1850027, 2018. 
[29] L. Xie, J. Ma, and H. Han, "Implications of stochastic demand and manufacturers' operational mode on retailer's mixed bundling strategy and its complexity analysis," Applied Mathematical Modelling, vol. 55, pp. 484-501, 2018.

[30] J. Ma and L. Sun, "Complexity analysis about nonlinear mixed oligopolies game based on production cooperation," IEEE Transactions on Control Systems Technology, vol. 26, no. 4, pp. 1532-1539, 2018.

[31] L. Xiao, J. Liu, Q. Li, N. B. Mandayam, and H. V. Poor, "Usercentric view of jamming games in cognitive radio networks," IEEE Transactions on Information Forensics and Security, vol. 10, no. 12, pp. 2578-2590, 2015.

[32] L. Xiao, Y. Chen, W. S. Lin, and K. J. R. Liu, "Indirect reciprocity security game for large-scale wireless networks," IEEE Transactions on Information Forensics and Security, vol. 7, no. 4, pp. 1368-1380, 2012.

[33] Y. Huang and Q. Li, "The entropy complexity of an asymmetric dual-channel supply chain with probabilistic selling," Entropy, vol. 20, no. 7, p. 543, 2018.

[34] F. Wu and J. Ma, "The equilibrium, complexity analysis and control in epiphytic supply chain with product horizontal diversification," Nonlinear Dynamics, vol. 93, no. 4, pp. 2145-2158, 2018.

[35] J. Ma, H. Ren, M. Yu, and M. Zhu, "Research on the complexity and chaos control about a closed-loop supply chain with dual-channel recycling and uncertain consumer perception," Complexity, vol. 2018, Article ID 9853635, 13 pages, 2018.

[36] J. Ma and F. Si, "Complex dynamics of a continuous Bertrand duopoly game model with two-stage delay," Entropy, vol. 18, no. 7 , p. $266,2016$. 


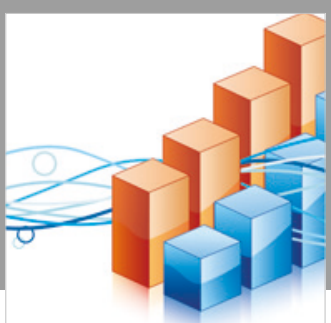

Advances in

Operations Research

\section{-n-m}
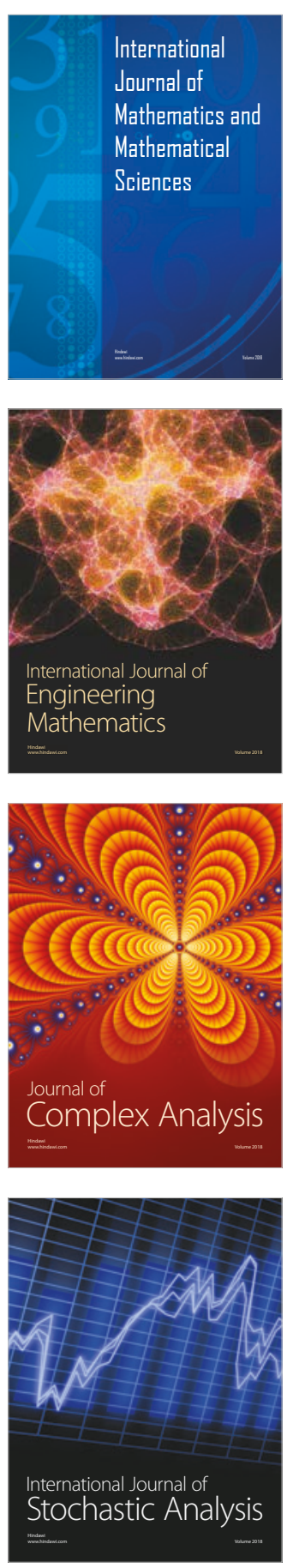
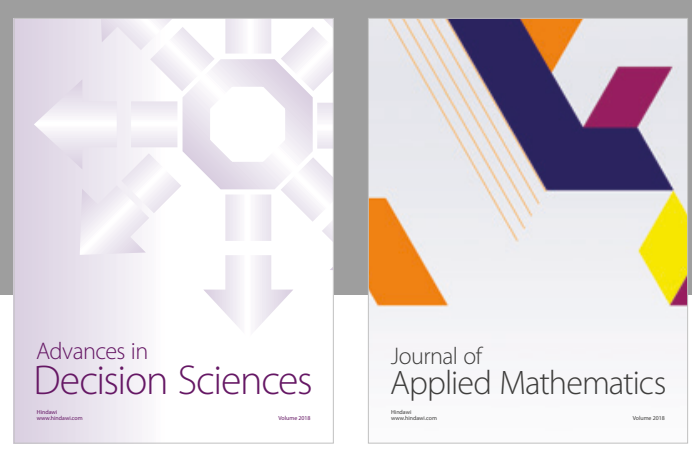

Journal of

Applied Mathematics
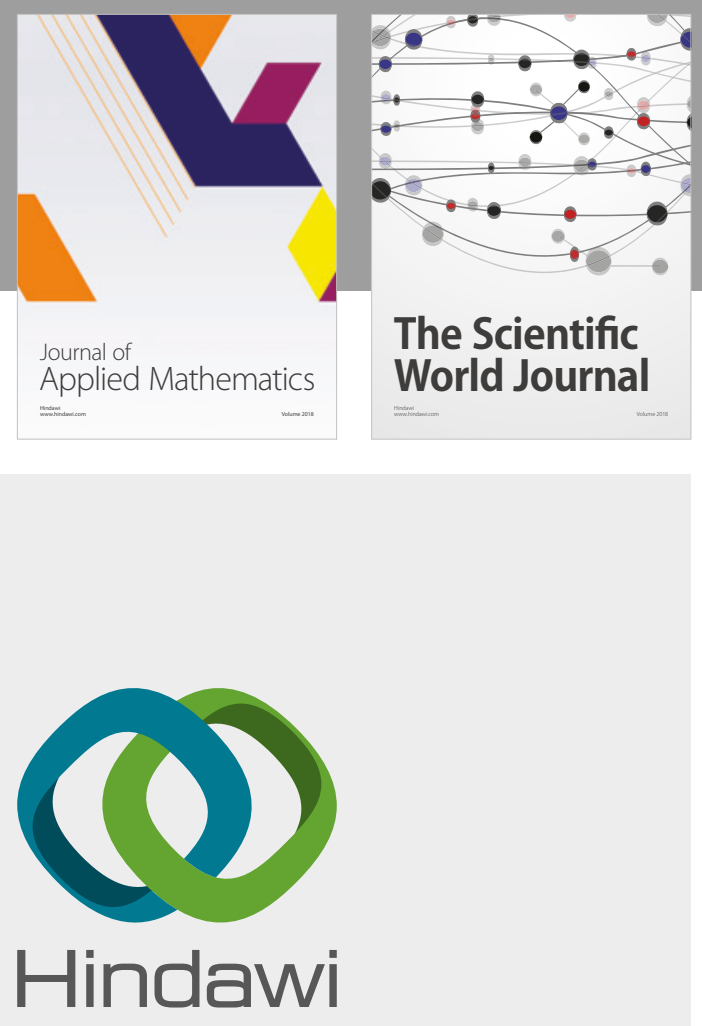

Submit your manuscripts at

www.hindawi.com

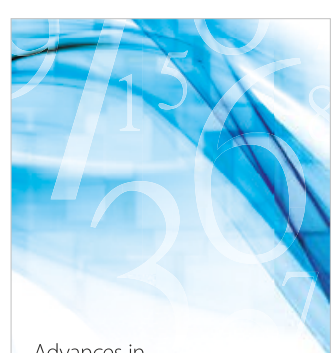

Advances in
Numerical Analysis
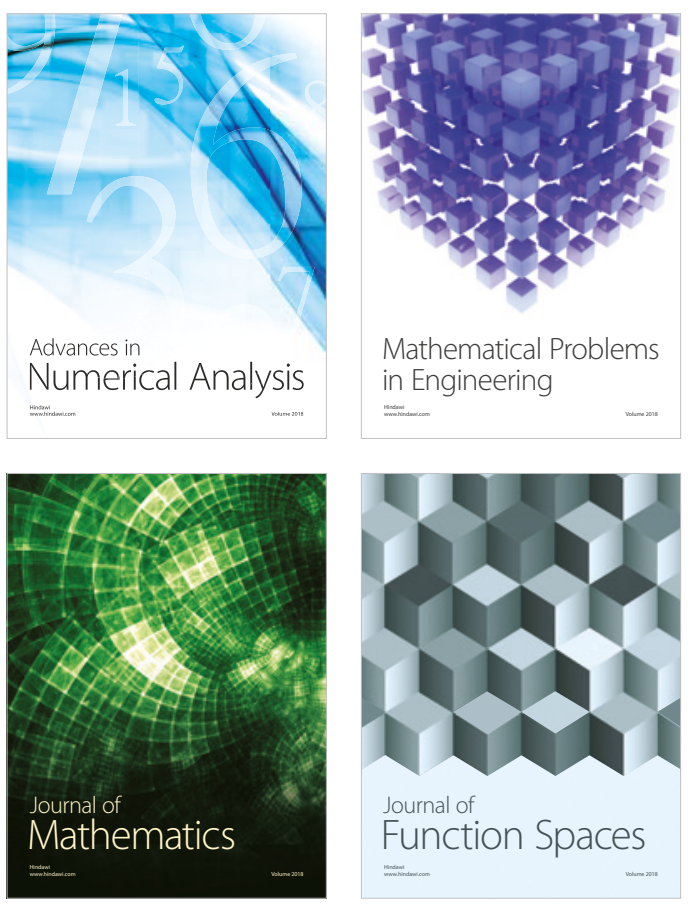

Mathematical Problems in Engineering

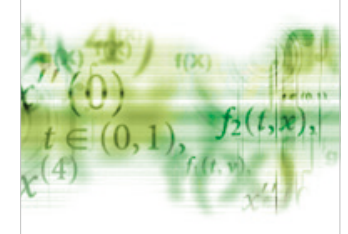

International Journal of

Differential Equations

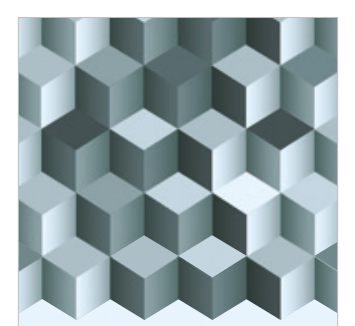

Journal of

Function Spaces
The Scientific

World Journal

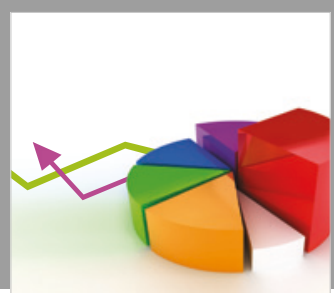

Journal of

Probability and Statistics
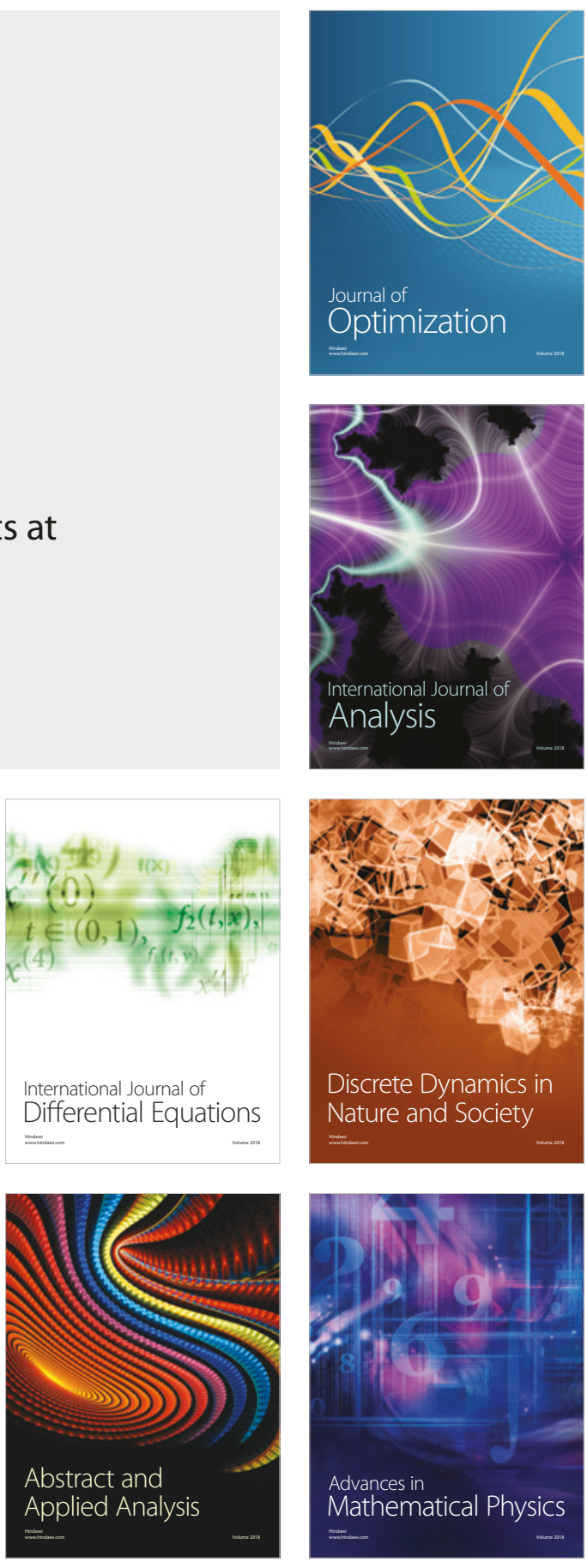